\title{
Novos registros na distribuição geográfica de anuros na Floresta com Araucária e considerações sobre suas vocalizações
}

\author{
Carlos Eduardo Conte ${ }^{1,7}$, Fausto Nomura ${ }^{2}$, Reginaldo Assêncio Machado ${ }^{3}$, \\ Axel Kwet ${ }^{4}$, Rodrigo Lingnau ${ }^{5}$ \& Denise de Cerqueira Rossa-Feres ${ }^{6}$ \\ ${ }^{1}$ Programa de Pós-graduação em Biologia Animal, Universidade Estadual Paulista - UNESP, \\ Rua Cristóvão Colombo, 2265, CEP 15054-000, São José do Rio Preto, SP, Brasil \\ ${ }^{2}$ Laboratório de Comportamento Animal e Herpetologia, Departamento de Ecologia, \\ Universidade Federal de Goiás - UFG, \\ Rod. Goiânia-Nerópolis, Km 5, CP 131, CEP 74001-970, Goiânia, GO, Brasil \\ ${ }^{3}$ Laboratório de Herpetologia, Centro Multidisciplinar, Campus Floresta, \\ Universidade Federal do Acre - UFAC, \\ CEP 69980-000, Cruzeiro do Sul, AC, Brasil \\ ${ }^{4}$ Staatliches Museum für Naturkunde Stuttgart, Zoology, Rosenstein 1, D-70191 Stuttgart, Germany \\ ${ }^{5}$ Universidade Tecnológica Federal do Paraná - UTFPR, \\ Linha Santa Bárbara, s/n, CEP 85601-971, Francisco Beltrão, PR, Brasil \\ ${ }^{6}$ Departamento de Zoologia e Botânica, Universidade Estadual Paulista - UNESP, \\ Rua Cristóvão Colombo, 2265, CEP 15054-000, São José do Rio Preto, SP, Brasil \\ ${ }^{7}$ Autor para correspondência: Carlos Eduardo Conte, e-mail: kadu_conte@yahoo.com.br
}

CONTE, C.E., NOMURA, F., MACHADO, R.A., KWET, A., LINGNAU, R. \& ROSSA-FERES, D.C. New records in the geographic distribution range of the anurans of the Araucaria Forest and considerations on their vocalizations. Biota Neotrop. 10(2): http://www.biotaneotropica.org.br/v10n2/en/abstract?inventory+ bn01110022010.

\begin{abstract}
Studies involving bioacoustics analysis turned possible the identification of complex species groups, as well as the description and differentiation of cryptic species. In order to increase the knowledge on the species composition of amphibians in Araucaria Forests, we sampled eleven areas in the states of Paraná and Santa Catarina, which significantly increased the geographic distribution range of eight amphibian species: Ischnocnema henselii, Dendropsophus anceps, a currently classified as critically endangered in Paraná State, D. nahdereri, Scinax granulatus, Trachycephalus dibernardoi, Pseudis cardosoi, Leptodactylus araucaria and L. nanus. Some of the new records represent corrections of previous identifications for example: Ischnocnema henselii is a cryptic species with some populations in Paraná that have been previously mistaken to I. guentheri; Trachycephalus dibernardoi was mistaken for T. imitatrix and Leptodactylus nanus to L. marmoratus. We also characterize and describe the calls of all these species.

Keywords: geographic distribution, Amphibia, Ischnocnema henselii, Dendropsophus anceps, Dendropsophus nahdereri, Pseudis cardosoi, Scinax granulatus, Trachycephalus dibernardoi, Leptodactylus araucaria, Leptodactylus nanus, Atlantic Forest, Paraná, Santa Catarina.
\end{abstract}

CONTE, C.E., NOMURA, F., MACHADO, R.A., KWET, A., LINGNAU, R. \& ROSSA-FERES, D.C. Novos registros na distribuição geográfica de anuros na Floresta com Araucária e considerações sobre suas vocalizações. Biota Neotrop. 10(2): http://www.biotaneotropica.org.br/v10n2/pt/abstract?inventory+bn01110022010.

Resumo: Estudos envolvendo análises bioacústicas têm possibilitado a identificação de espécies pertencentes a grupos complexos, bem como a descrição e diferenciação de espécies crípticas. Recorrendo a esta ferramenta e com o objetivo de aumentar o conhecimento sobre a composição de espécies de anfíbios em áreas de Floresta com Araucária, foram amostradas 11 áreas nos estados do Paraná e Santa Catarina. Os resultados ampliaram significativamente o conhecimento da distribuição geográfica de oito espécies de anfíbios anuros: Ischnocnema henselii, Dendropsophus anceps, atualmente classificada como criticamente ameaçada no Estado do Paraná, D. nahdereri, Scinax granulatus, Trachycephalus dibernardoi, Pseudis cardosoi, Leptodactylus araucaria $\mathrm{e}$ L. nanus. Alguns destes registros representam correções em identificações anteriores: Ischnocnema henselii é uma espécie críptica e algumas populações até o momento eram confundidas no Paraná com I. guentheri; Trachycephalus dibernardoi era identificada como T. imitatrix e Leptodactylus nanus como L. marmoratus. A caracterização e descrição dos cantos destas espécies também são apresentadas.

Palavras-chave: distribuição geográfica, Amphibia, Ischnocnema henselii, Dendropsophus anceps, Dendropsophus nahdereri, Pseudis cardosoi, Scinax granulatus, Trachycephalus dibernardoi, Leptodactylus araucaria, Leptodactylus nanus, Floresta Atlântica, Paraná, Santa Catarina. 


\section{Introdução}

O Brasil é o país com a maior diversidade de anuros do planeta, com 877 espécies reconhecidas (Sociedade Brasileira de Herpetologia 2010). Como em muitas regiões tropicais, o principal fator de risco para essa diversidade é a perda de habitats, causada pelo crescimento das populações humanas (Silvano \& Segalla 2005, Fonseca et al. 2008). A relevância do impacto é tamanha que das 16 espécies que se encontram em alguma categoria de ameaça no país - número provavelmente subestimado $-75 \%$ decorrem da destruição do ambiente (Haddad 2008). Como complicador, uma grande quantidade dessas espécies estão categorizadas como "dados insuficientes" em listas vermelhas regionais e/ou nacional, refletindo o estágio inicial em que se encontra o conhecimento sobre a anurofauna em grande parte do território brasileiro.

Historicamente, os esforços têm se concentrado nas regiões costeiras e ao longo dos grandes rios, sendo negligenciados para os planaltos interioranos (Haddad 1998). Embora um rápido e grande avanço nas pesquisas com anfíbios tenha ocorrido nos últimos anos em áreas pouco amostradas (e.g. Conte \& Rossa-Feres 2006, Bastazini et al. 2007, Canelas \& Bertoluci 2007, Menin et al. 2008, Santos et al. 2009, Lucas \& Fortes 2008), ainda existem lacunas geográficas a serem preenchidas. A Mata Atlântica é, ainda, um dos biomas cuja anurofauna pode ser considerada pouco conhecida em alguns de seus ecossistemas (Haddad \& Sazima 1992, Pombal Jr. \& Gordo 2004, Silvano \& Segalla 2005), como a Floresta com Araucária (= Floresta Ombrófila Mista), que carece de inventários, estudos ecológicos de médio e longo prazo (Conte \& Machado 2005, Lucas \& Fortes 2008) incluindo aqueles com bioacústica (Lingnau et al. 2004, Conte et al. 2005).

A atividade de vocalização dos anuros é uma característica típica do grupo (Duellman \& Trueb 1986, Wells 2007) e muitos estudos demonstraram que ela atua como uma importante barreira para a troca de genes entre espécies distintas (Drewry \& Randy 1983), podendo auxiliar na identificação e descrição de espécies crípticas (Channing et al. 2002). Assim, táxons morfologicamente similares podem ser distinguidos em função de características dos seus cantos como, por exemplo, Eleutherodactylus coqui e E. portoricensis (Porto Rico; Thomas 1966) e espécies crípticas dos gêneros Breviceps e Hyperolius (África; Minter 1997, Channing et al. 2002). No Brasil, o registro e a caracterização do canto de anuros também podem auxiliar na identificação de complexos de espécies crípticas (Heyer 1984) e na designação correta daquelas antes confundidas morfologicamente. Entretanto, os anuros não apresentam apenas um tipo de vocalização, emitindo sons distintos em contextos sociais e ecológicos diferentes
(Duellman \& Trueb 1986, Wells 2007). Entre os tipos de canto identificados, o de anúncio é geralmente considerado como um sinal de múltiplas mensagens, empregado em diferentes contextos sociais, enquanto que o canto territorial é utilizado apenas em encontros agonísticos entre machos (Wells 2007).

Este estudo tem como objetivo relatar ampliações e preenchimentos de lacunas na ocorrência de oito espécies de anfíbios em áreas de Floresta com Araucária do sul do país e apresentar uma síntese da distribuição conhecida no Brasil, juntamente com a descrição e análise de seus cantos de anúncio. Ainda, é apresentado o canto territorial de Ischnocnema henselii, Dendropsophus anceps e Pseudis cardosoi. Adicionalmente, para estas três espécies, nós comparamos o canto territorial e de anúncio de cada uma delas para identificar quais componentes do canto são modulados em função do contexto, a fim de testar a hipótese de que cantos de anúncio transmitem mensagens múltiplas enquanto que cantos territoriais apresentam informações redundantes.

\section{Material e Métodos}

Os dados aqui apresentados foram obtidos ao longo de sete anos (2003-2009) de incursões ao campo, nas quais os ambientes foram amostrados durante o período noturno, sendo as espécies registradas por busca visual e auditiva (Tabela 1). Foram realizadas amostragens em onze municípios localizados nas regiões sudeste e centro sul do Estado do Paraná e centro norte de Santa Catarina (Tabela 1). Além disso, foram realizadas novas incursões em localidades cuja anurofauna já havia sido inventariada, em Tijucas do Sul (Conte \& Machado 2005), São José dos Pinhais (Conte \& Rossa-Feres 2006) e Fazenda Rio Grande (Conte \& Rossa-Feres 2007), para obtenção do registro do canto de algumas espécies, com o intuito de reavaliar suas identificações.

Exemplares-testemunho foram capturados manualmente, anestesiados e mortos em álcool fraco (10\%). O comprimento rostro-cloacal (CRC) de todos os indivíduos foram medidos com paquímetro $(0,05 \mathrm{~mm})$ e depositados na Coleção Científica do Departamento de Zoologia e Botânica da UNESP, Campus de São José do Rio Preto (DZSJRP), São Paulo (licenças ICMbio números 02026.002574/2006-53 e 13282-1). As vocalizações das espécies foram registradas com microfone semi-direcional Sennheiser ME66 acoplado a um gravador Marantz PMD222 e a temperatura e umidade relativa do ar foram medidas com o auxílio de um termohigrômetro HT 7020. As vocalizações foram digitalizadas em frequência de amostragem de $44.100 \mathrm{~Hz}$, com resolução de 16 bits, FFT, editadas e analisadas no

Tabela 1. Lista das localidades amostradas nos estados de Santa Catarina e Paraná, Brasil, durante o período de 2003 a 2009. Tipos de Unidades de Conservação: APA = Área de Proteção Ambiental; FLONA = Floresta Nacional; REVS = Refúgio da Vida Silvestre; PARMU = Parque Municipal; PARNA = Parque Nacional. Formação Vegetal: FOM = Floresta Ombrófila Mista e FES = Floresta Estacional Semidecidual.

Table 1. List of sampling sites in the states of Santa Catarina and Paraná, Brazil, during the period 2003 to 2009. APA = Área de Proteção Ambiental, FLONA = Floresta Nacional, REVS = Refúgio da Vida Silvestre, PARMU = Parque Municipal; PARNA = Parque Nacional; Vegetation types: FOM = Araucaria forest and FES $=$ Semideciduous forest.

\begin{tabular}{|c|c|c|c|c|}
\hline $\begin{array}{l}\text { Localidade(s) } \\
\text { estado }\end{array}$ & $\begin{array}{l}\text { Unidade de } \\
\text { conservação }\end{array}$ & $\begin{array}{c}\text { Formação } \\
\text { vegetal }\end{array}$ & Coordenadas & $\begin{array}{l}\text { Esforço amostral - } \\
\text { meses/horas }\end{array}$ \\
\hline Candói, PR & - & FOM, FES e Campos & $25^{\circ} 38^{\prime} \mathrm{S}$ e $51^{\circ} 58^{\prime} \mathrm{O}$ & $12 / 125$ \\
\hline Fernandes Pinheiro, PR & FLONA de Irati & FOM & $25^{\circ} 23^{\prime} \mathrm{S}$ e $50^{\circ} 34^{\prime} \mathrm{O}$ & $12 / 100$ \\
\hline Figueira/Ibaiti, PR & - & FOM e FES & $23^{\circ} 51^{\prime} \mathrm{S}$ e $50^{\circ} 23^{\prime} \mathrm{O}$ & $12 / 78$ \\
\hline General Carneiro, PR & - & FOM e Campos & $26^{\circ} 22^{\prime} \mathrm{S}$ e $51^{\circ} 22^{\prime} \mathrm{O}$ & $13 / 208$ \\
\hline Guarapuava, PR & APA Serra da Esperança & FOM & $25^{\circ} 16^{\prime} \mathrm{S}$ e $51^{\circ} 71^{\prime} \mathrm{O}$ & $12 / 78$ \\
\hline Palmas, PR & REVS dos Campos de Palmas & Campos e FOM & $26^{\circ} 31^{\prime} \mathrm{S}$ e $51^{\circ} 38^{\prime} \mathrm{O}$ & $12 / 100$ \\
\hline Rio Negro, PR & PARMU São Luis de Tolosa & FOM & $26^{\circ} 05^{\prime} \mathrm{S}$ e $49^{\circ} 48^{\prime} \mathrm{O}$ & $12 / 100$ \\
\hline Ponte Serrada/Passos Maia, SC & PARNA das Araucárias & FOM & $26^{\circ} 47^{\prime} \mathrm{S}$ e $51^{\circ} 54^{\prime} \mathrm{O}$ & $13 / 156$ \\
\hline Vargem Bonita, SC & - & FOM e Campos & $26^{\circ} 53^{\prime} \mathrm{S}$ e $51^{\circ} 48^{\prime} \mathrm{O}$ & $13 / 156$ \\
\hline
\end{tabular}


programa Cool Edit, versão 96 (Syntryllium Software Corporation) Os parâmetros acústicos medidos seguiram Lingnau et al. (2004) e Martins et al. (2006): frequência máxima (Hz), frequência mínima $(\mathrm{Hz})$, frequência dominante $(\mathrm{Hz})$, duração da nota $(\mathrm{s})$, número de pulsos, taxa de repetição (notas/s) e intervalo entre notas (s).

Os cantos de anúncio e territorial de Ischnocnema henselii, Dendropsophus anceps e Pseudis cardosoi, foram comparados por análise multivariada. A normalidade multivariada é uma premissa de muitos testes multivariados. Assim, os dados utilizados nas comparações entre os cantos foram testados quanto a essa premissa pelos testes de Mardia e Kurtosis para homogeneidade de variância
(Mardia 1970) e o teste geral de Doornik \& Hansen (2008). Quando pelo menos um destes testes apresentou um grande desvio da normalidade (diferença significativa de 5\%) a distribuição foi considerada como significativamente não-normal e os conjuntos de dados foram então comparados por Análise de Similaridade (ANOSIM). A ANOSIM é um teste não paramétrico que mede a diferença entre dois ou mais grupos, a partir de qualquer medida de distância, que são convertidas em postos e comparadas dentro e entre grupos (Clarke 1993). Neste estudo, foi utilizada como medida de distância o índice de Bray-Curtis. O teste a posteriori é realizado por meio de uma comparação par-a-par utilizando a ANOSIM, com a correção de Bonferroni para múltiplas comparações
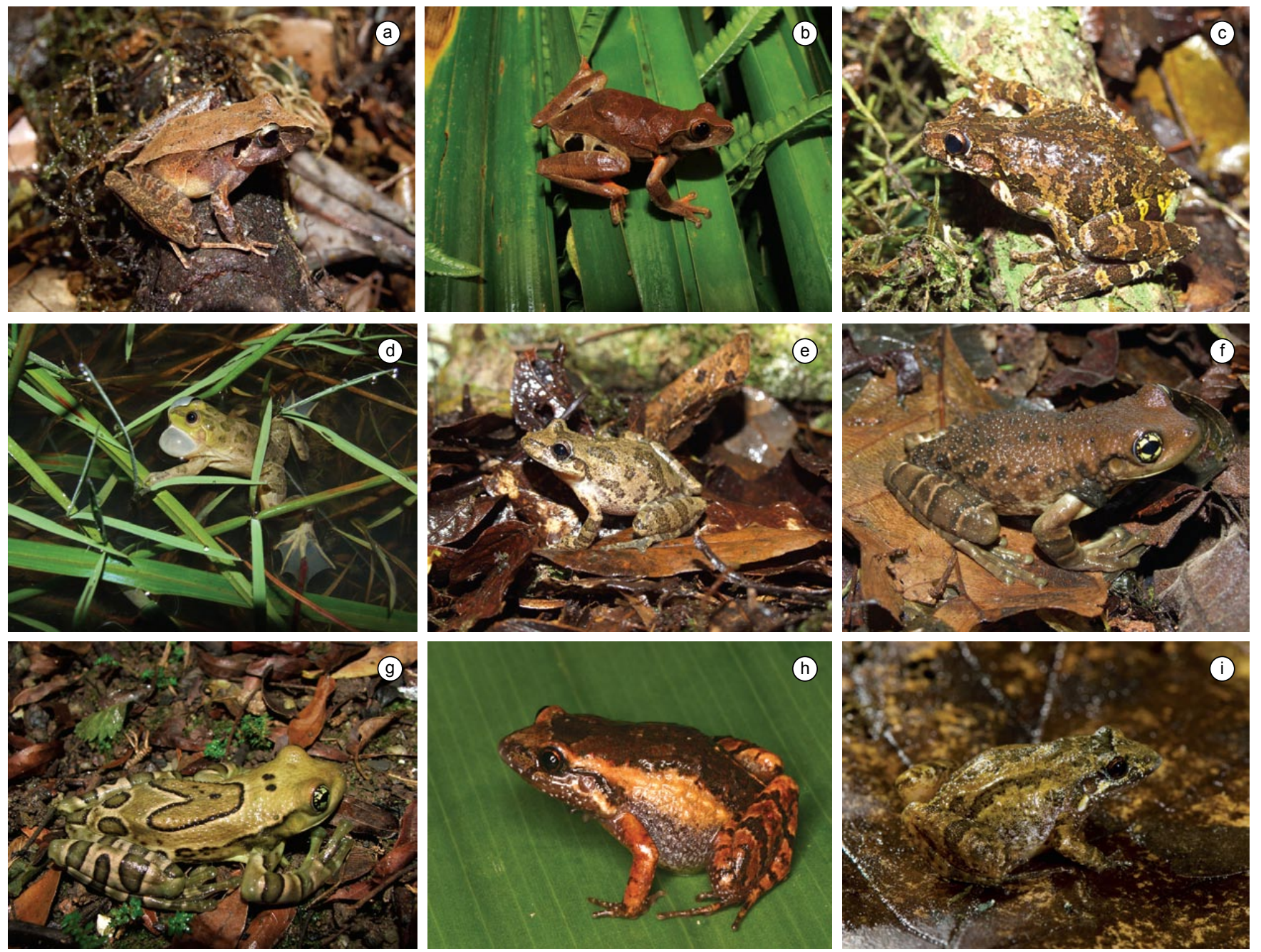

Figura 1. Distribuição geográfica para as espécies de anfíbios anuros estudadas e o respectivo local de coleta. A- Vista dorso-lateral de uma fêmea de Ischnocnema henselii registrada na FLONA de Irati, Paraná; B- Vista lateral de um macho de Dendropsophus anceps registrado em Figueira, Paraná; C- Vista dorso-lateral de um macho de D. nahdereri registrado em Vargem Bonita, Santa Catarina; D- Vista dorso-lateral de um macho de Pseudis cardosoi em atividade de vocalização, registrado no REVS dos Campos de Palmas, Paraná; E- Vista dorso-lateral de um macho de Scinax granulatus no REVS dos Campos de Palmas, Paraná; F- Vista lateral de um macho de Trachycephalus dibernardoi registrado em Telêmaco Borba, Paraná e G- Vista dorso-lateral de um macho de T. dibernardoi registrado no PARNA das Araucárias, Santa Catarina; H- Vista dorso-lateral de um macho de Leptodactylus araucaria registrado em Florianópolis, Santa Catarina; I- Vista dorso-lateral de um macho de L. nanus registrado no PARMU São Luis de Tolosa, Paraná. Fotos: A-G: C. E. Conte, H: A. Kwet e I: L. Scheuermann.

Figure 1. Anuran species, whose geographic distribution range has been expanded. A- Dorsolateral view of a female Ischnocnema henselii from Floresta Nacional de Irati, Paraná State; B- Lateral view of a male Dendropsophus anceps from Figueira, Paraná State; C- Dorsolateral view of a male D. nahdereri from Vargem Bonita, Santa Catarina State; D- Dorsolateral view of a male Pseudis cardosoi in calling activity, and E- Dorsalateral view of a male Scinax granulatus from Refúgio da Vida Silvestre dos Campos de Palmas, Paraná State; F- Lateral view of a male Trachycephalus dibernardoi from Telêmaco Borba, Paraná State and, G- Dorsolateral view of a male T. dibernardoi from Parque Nacional das Araucárias, Santa Catarina State; H- Dorsolateral view of a male of Leptodactylus araucaria from Florianópolis, Santa Catarina State and, I- Dorsolateral view of a male of L. nanus from Parque Municipal São Luis de Tolosa, Paraná State. Photos: A-G. C. E. Conte, H. A. Kwet e I. L. Scheuermann. 
(Clarke 1993), sendo que as diferenças foram consideradas significativas quando $\mathrm{p} \leq 0,05$. Para representar graficamente as diferenças entre os grupos, foi utilizada análise de escalonamento multidimensional não métrico (NMDS - Clarke \& Warwick 1994). O algoritmo usado para os cálculos computacionais é descrito por Kruskal (1964). O ponto inicial desta análise é a matriz de similaridade entre os grupos comparados, no caso, as matrizes de similaridade construídas a partir das características temporais e espectrais dos cantos de anúncio e territorial, utilizando o índice de Bray-Curtis. O mapeamento das variáveis explanatórias para a distribuição dos cantos no espaço bi-dimensional foi realizada por meio de uma análise de regressão linear simples entre os autovalores dos eixos 1 e 2 da NMDS com as características espectrais e temporais dos cantos.

No caso dos dados apresentarem uma distribuição normal, a comparação entre os cantos foi realizada por meio de análise de variância multivariada (MANOVA). A MANOVA é uma versão multivariada da ANOVA e compara a diferença entre médias de vários grupos (Hand \& Taylor 1987). Para representar graficamente as diferenças entres os cantos de anúncio e territorial foi aplicada análise de covariância (CVA). Formalmente, a CVA é um caso especial de correlação na qual o conjunto de variáveis preditoras é resumido a uma única variável nominal definindo as classes (Ter Braak 1994). Para representar graficamente as diferenças entres os cantos de anúncio e territorial foi aplicada análise de covariância. Para verificar diferenças entre as notas de um mesmo tipo de canto, foi aplicado o teste T Student, sendo considerados significativos valores de $\mathrm{p} \leq 0,05$ (Zar 1999).

Para confecção dos mapas de distribuição das espécies, além da revisão da literatura especializada, foi realizado o levantamento de material testemunho depositado nas seguintes coleções: coleção de Amphibia do Departamento de Zoologia e Botânica/UNESP - São José do Rio Preto (DZSJRP), Coleção de Amphibia do Museu Nacional/ UFRJ - Rio de Janeiro (MNRJ), Coleção de Amphibia do Museu de Zoologia/USP - São Paulo (MZUSP), coleção de Amphibia Célio F. B. Haddad/UNESP - Rio Claro (CFBH) e Coleção de Amphibia do Museu de Ciências e Tecnologia/PUCRS - Porto Alegre (MCP). Essas coleções estão entre as mais importantes do país, com representativo número de espécimes de anuros de várias regiões do Brasil.

\section{Resultados e Discussão}

Foi possível registrar quatro novas ocorrências para o Estado do Paraná e quatro ampliações de distribuição geográfica para os estados do Paraná e Santa Catarina.

\section{Ischnocnema henselii (Peters, 1870) - Figura 1a}

Comentários taxonômicos. Descrita por Peters (1870) com o nome de "Hylodes henselii" com base em indivíduos coletados em Porto Alegre, Rio Grande do Sul. Heyer (1984) arbitrariamente designou o holótipo de Eleutherodactylus guentheri como o neótipo de Hylodes henselii por considerar o holótipo de $H$. henselii perdido. Entretanto o holótipo de H. henselii foi recentemente encontrado no museu de Berlim (Bauer et al. 1995) e revisto por Kwet \& Solé (2005) que, após exame do exemplar tipo e análise do canto de populações de diversas localidades no Sul do Brasil e Argentina, redescreveram Hylodes henselii como Eleutherodactylus henselii (= Ischnocnema henselii - ver Heinicke et al. 2007).

Comprimento rostro-cloacal. Foram medidos 11 machos e cinco fêmeas provenientes do Paraná e Santa Catarina (Anexo 1) e o CRC foi: machos $=23,06 \pm 1,95 \mathrm{~mm}(21,61-26,40 \mathrm{~mm})$; fêmeas $=34,5 \pm 1,83 \mathrm{~mm}(32,3-36,4 \mathrm{~mm})$. Essa variação de tamanho está contida na registrada por Kwet \& Solé (2005).

Distribuição geográfica. Kwet \& Solé (2005) consideraram a ocorrência da espécie no Brasil restrita ao nordeste do Rio Grande do Sul e leste de Santa Catarina. Posteriormente, Lingnau (2008) ampliou a distribuição para a região central de Santa Catarina, no município de Lebon Régis.

Novos registros. Neste estudo, foram identificadas pela análise do canto de anúncio, quatro populações de Ischnocnema henselii no Estado do Paraná que estavam erroneamente identificadas como I. guentheri, nos municípios de Telêmaco Borba (Rocha et al. 2003), Tijucas do Sul (Conte \& Machado 2005), São José dos Pinhais (Conte \& Rossa-Feres 2006) e Fazenda Rio Grande (Conte \& Rossa-Feres 2007). Além destes registros, outras quatro novas populações foram identificadas, duas em Santa Catarina (municípios de Vargem Bonita e no PARNA das Araucárias) e duas no Paraná (município de Candói e na FLONA de Irati) (Figura 2).

História natural. Machos foram observados em atividade de vocalização apenas nos meses de novembro e dezembro, sempre no interior de remanescentes florestais preservados, onde vocalizavam empoleirados sobre vegetação herbácea e arbustiva ou no solo.

Análise do canto. Foram obtidas dez gravações dos cantos de anúncio e territorial de cinco indivíduos provenientes de São José dos Pinhais, Telêmaco Borba, Candói, Estado do Paraná e Vargem Bonita e PARNA das Araucárias, Estado de Santa Catarina. O canto de anúncio é composto por uma longa seqüência de notas emitidas rapidamente, aumentando de intensidade do início para o fim, com uma diferença de $0,11 \mathrm{~s}$ [início: 0,22 $\pm 0,11 \mathrm{~s}$

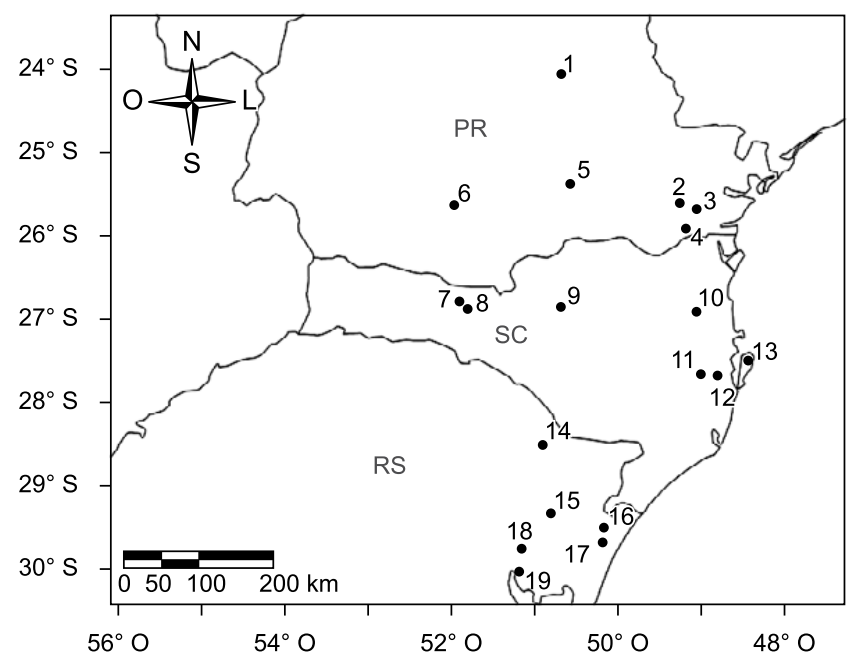

Figura 2. Mapa atualizado da distribuição geográfica de Ischnocnema henselii. 1. Telêmaco Borba 2. Fazenda Rio Grande, 3. São José dos Pinhais, 4. Tijucas do Sul, 5. FLONA de Irati, 6. Candói, 7. PARNA das Araucárias, 8. Vargem Bonita, 9. Lebon Régis, 10. Blumenau, 11. Rancho Queimado, 12. Águas Mornas, 13. Florianópolis, 14. Vacaria, 15. Canela, 16. São Francisco de Paula, 17. Maquiné, 18. São Leopoldo e 19. Porto Alegre. Dados extraídos de: 1-8. Presente estudo; 9. Lingnau (2008); 11-13 e 15-19. Kwet \& Solé (2005); 10 e 14. Coleção MCP.

Figure 2. Map of the current geographic distribution of Ischnocnema henselii. 1. Telêmaco Borba 2. Fazenda Rio Grande, 3. São José dos Pinhais, 4. Tijucas do Sul, 5. Fernandes Pinheiro, 6. Candói, 7. Parque Nacional das Araucárias, 8. Vargem Bonita, 9. Lebon Régis, 10. Blumenau, 11. Rancho Queimado, 12. Águas Mornas, 13. Florianópolis, 14. Vacaria, 15. Canela, 16. São Francisco de Paula, 17. Maquiné, 18. São Leopoldo and 19. Porto Alegre. Data from: 1-8. Present study; 9. Lingnau (2008); 11-13 and 15-19. Kwet \& Solé (2005); 10 and 14. MCP collection. 
$(0,127-0,643 \mathrm{~s})$; final: $0,11 \pm 0,01 \mathrm{~s}(0,078-0,155) ; \mathrm{t}=8,2$ $\mathrm{gl}=156, \mathrm{p}=0,00 ; \mathrm{n}=200$ notas] (Figuras $3 \mathrm{a}, \mathrm{b}$ ). $\mathrm{O}$ canto de anúncio apresenta dois tipos de notas, definidas por características temporais: notas curtas com aproximadamente $0,012 \mathrm{~s}$ e notas longas com aproximadamente $0,027 \mathrm{~s}$, sendo que as notas curtas são emitidas com maior frequência na metade inicial do canto e as notas longas na metade final (Figuras 3c, d). A diferença entre as notas curtas e longas é de $0,015 \mathrm{~s}(\mathrm{t}=-24,1 ; \mathrm{gL}=208$; $\mathrm{p}=0,00)$. Já o canto territorial tem duração de aproximadamente $0,62 \mathrm{~s}$, sendo formado por seis notas pulsionadas (Figuras 3e, f). Em ambos os tipos de canto houve uma variação no número de pulsos, com notas formadas com até cinco pulsos e, nesse caso, alguns pulsos sobrepostos.

As variáveis utilizadas para comparação do canto territorial e o de anúncio (Tabela 2) diferiram da distribuição normal (homogeneidade de variância $=15,93, \mathrm{GL}=56, \mathrm{p}=0,585$; kurtosis $=42,71, \mathrm{p}=0,2276$; Doornik \& Hansen $=22,62$, $p=0,031)$ e os cantos diferiram entre si especialmente quanto aos parâmetros de frequência máxima $(r=0,92)$, duração do canto $(\mathrm{r}=-0,87)$, número de notas $(\mathrm{r}=-0,85)$ e frequência dominante $(\mathrm{r}=0,72)$, (ANOSIM: $\mathrm{R}=0,85 ; \mathrm{p}<0,0001$; Figura 4).

Kwet \& Solé (2005) consideraram que o canto de I. henselii é composto por notas não pulsionadas. Em uma re-análise dos cantos gravados por Kwet \& Solé (2005), empregando os mesmos critérios utilizados neste estudo, observa-se dois a três pulsos por nota. A variação no número de pulsos também ocorre para outras espécies do gênero, como I. guentheri (Heyer et al. 1990), que apresenta notas não pulsionadas (ou "fracamente pulsionadas") e/ou com dois pulsos. A definição de pulso ou da variação no número de pulsos por nota não é clara e, deste modo, pode-se considerar que a diferença encontrada entre o número de pulsos por nota na descrição
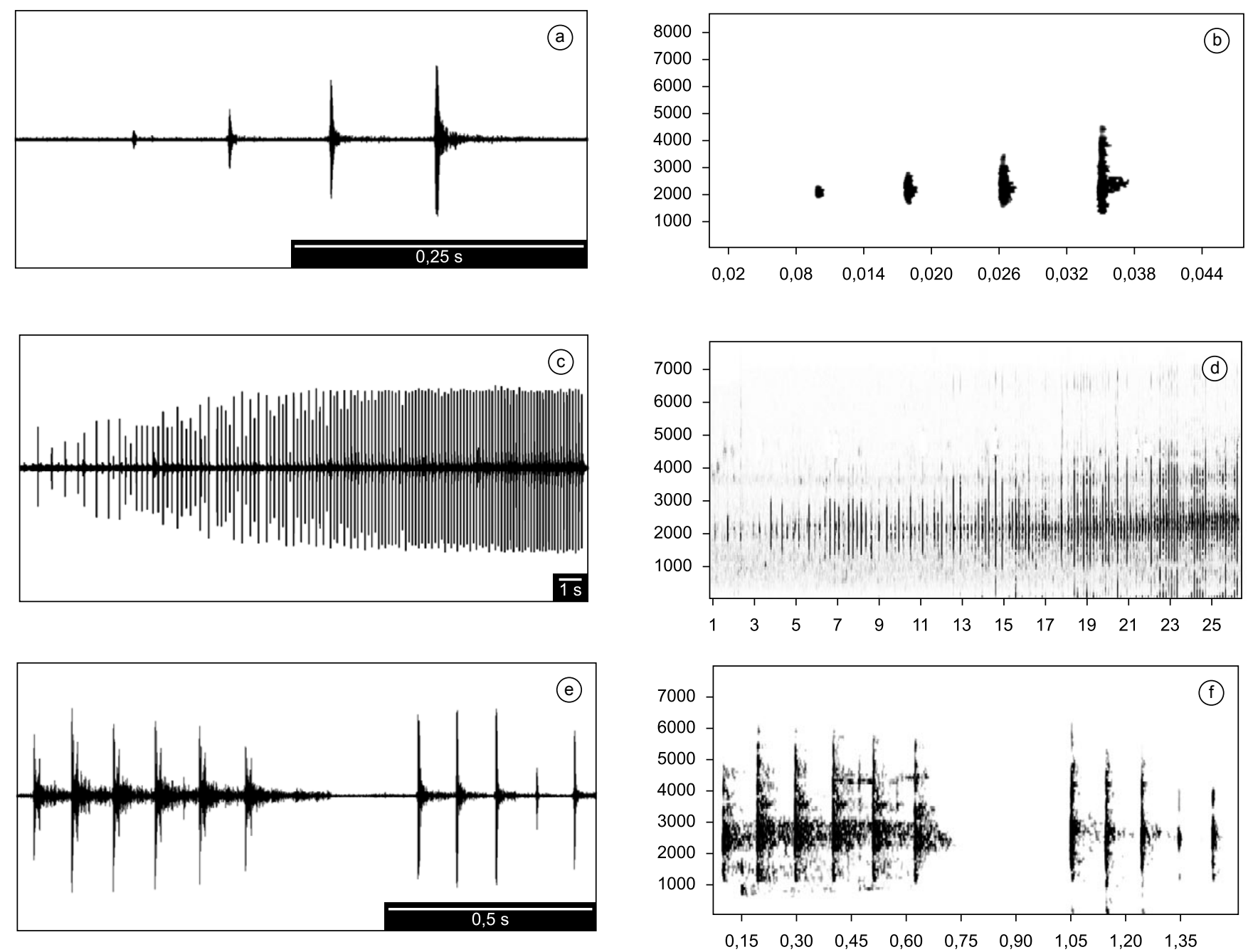

Figura 3. Canto de Ischnocnema henselii. a) Oscilograma, b) Sonograma de duas notas curtas e duas longas (1- nota curta com $0,008 \mathrm{~s}$ e frequência de 1.309 a $2.258 \mathrm{~Hz}$; 2- nota curta com $0,012 \mathrm{~s}$ e frequência de 1.669 a $2.779 \mathrm{~Hz}$; 3- nota longa com $0,020 \mathrm{~s}$ e frequência de 1.461 a 3.548 HZ; e 4 - nota longa com $0,032 \mathrm{~s}$ e frequência de $1.195 \mathrm{a} 4.800 \mathrm{~Hz}$ ); c) Oscilograma e d) Sonograma do canto de anúncio; e) Oscilograma e f) Sonograma do canto territorial. São José dos Pinhais, Paraná. Temperatura do ar: $15{ }^{\circ} \mathrm{C}$. Umidade relativa do ar: $84 \%$.

Figure 3. Call of Ischnocnema henselii. a) Oscilogram, b) Sonogram of two short notes and two long notes (1- short note with $0,008 \mathrm{~s}$ and frequency of 1.309 to $2.258 \mathrm{~Hz}$; 2- short note with $0,012 \mathrm{~s}$ and frequency of 1.669 to $2.779 \mathrm{~Hz}$; 3 - long note with $0,020 \mathrm{~s}$ and frequency of $1.461 \mathrm{Ho} 3.548 \mathrm{~Hz}$; and 4 - Long note with $0,032 \mathrm{~s}$ and frequency of 1.195 to $4.800 \mathrm{~Hz}$ ); c) Oscilogram and d) Sonogram of the advertisement call; e) Oscilogram and f) Sonogram of territorial call. São José dos Pinhais, Parana State. Air temperature: $15{ }^{\circ} \mathrm{C}$. Relative air humidity: $84 \%$. 
Tabela 2. Parâmetros bioacústicos do canto de anúncio de Ischnocnema henselii registrado em São José dos Pinhais e Telêmaco Borba, Paraná, Vargem Bonita e PARNA das Araucárias, Santa Catarina (Média \pm desvio padrão (amplitude); número de notas analisadas/número de indivíduos), e por Kwet \& Sole (2005) para diversas localidades dos estados de Santa Catarina e Rio Grande do Sul (amplitude).

Table 2. Bioacoustic parameters of the advertisement call of Ischnocnema henselii, recorded at São José dos Pinhais and Telêmaco Borba, Paraná State, Vargem Bonita and Parque Nacional das Araucárias, Santa Catarina State (Mean \pm standard deviation (range); number of notes analyzed / number of individuas), and by Kwet \& Solé (2005) at several localities in Santa Catarina and Rio Grande do Sul states (range).

\begin{tabular}{lccc}
\hline \multicolumn{1}{c}{ Parâmetros } & \multicolumn{2}{c}{ Canto de anúncio } & \multicolumn{1}{c}{$\begin{array}{c}\text { Canto territorial } \\
\text { (presente estudo) }\end{array}$} \\
\cline { 2 - 3 } & $24,9 \pm 2,60(20,57-26,5) ; 10 / 5$ & (Kwet \& Solé 2005) & $0,62 \pm 0,08(0,47-0,77) ; 10 / 2$ \\
Duração do canto & $126,5 \pm 24(98-182) ; 10 / 5$ & $86-170$ & $6,2 \pm 0,9(5-7) ; 10 / 2$ \\
Notas por canto & $2,45 \pm 1,08(1-4)$ & - & $3,43 \pm 1,22(1-5)$ \\
Número de pulsos & $0,012 \pm 0,002(0,006-0,019) ; 10 / 5$ & $0,035-0,06^{*}$ & $0,08 \pm 0,01(0,052-0,137) ; 10 / 2^{*}$ \\
Duração da nota curta & $0,027 \pm 0,005(0,02-0,047) ; 10 / 5$ & - & - \\
Duração da nota longa & $1.064,6 \pm 138,7(848,8-1.273) ; 10 / 5$ & - & $927,6 \pm 128,3(645,1-1062) ; 10 / 2$ \\
Frequência mínima & $4.809,4 \pm 447,5(4.282-5.671) ; 10 / 5$ & - & $5.990 \pm 362,9(5.218-6.470) ; 10 / 2$ \\
Frequência máxima & $2.287,9 \pm 145,5(2.128-2.501) ; 10 / 5$ & $2.200-3.100$ & $2.715 \pm 273,2(2.214,9-3.301) ; 10 / 2$ \\
Frequência dominante & $5,5 \pm 2,12(3-8,31) ; 11 / 2$ & $5-9$ & $0,10 \pm 0,004(0,09-0,11) ; 10 / 2$ \\
Taxa de repetição & $0,22 \pm 0,11(0,127-0,643) ; 200 / 5$ & $0,13-0,23$ & $0,015 \pm 0,009 *(0,002-0,061) ; 10 / 2$ \\
Intervalo entre notas, $1 / 3$ inicial & $0,11 \pm 0,01(0,078-0,155) ; 200 / 5$ & $0,07-0,13$ & - \\
Intervalo entre notas, $1 / 3$ final & &
\end{tabular}

* Sem distinção entre as notas

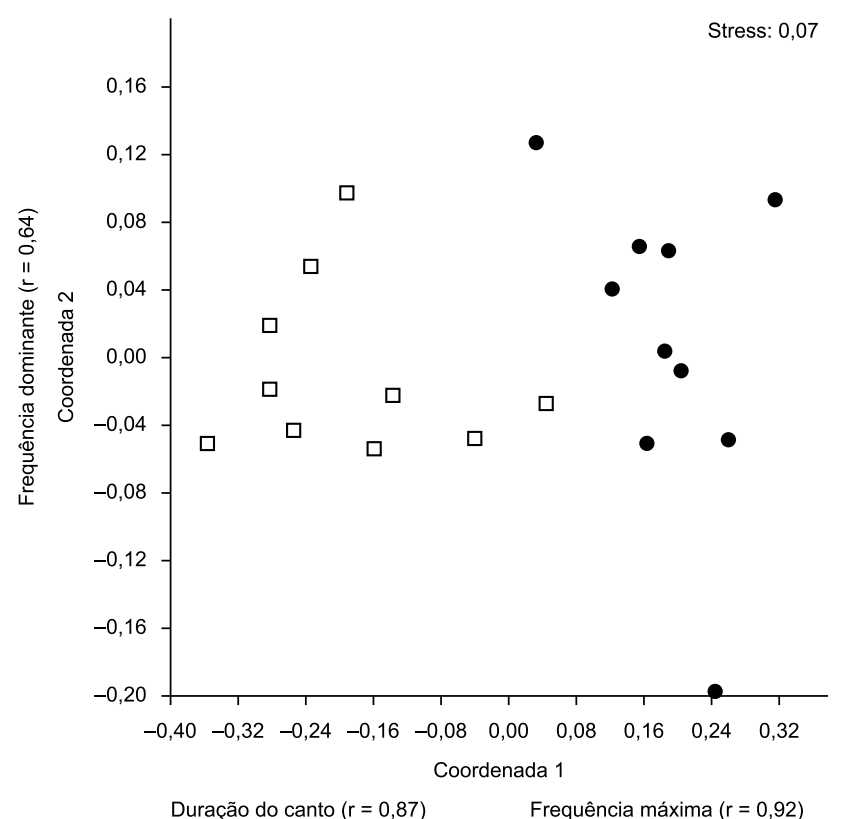

Duração do canto $(r=0,87)$
Número de notas $(r=-0,85)$

Frequência máxima $(r=0,92)$

Frequência dominante $(r=0,72)$

Figura 4. Análise escalonada multidimensional não-métrica para os cantos territoriais e de anúncio de Ischnocnema henselii. $\bullet=$ canto de anúncio e $\square=$ canto territorial.

Figure 4. Non-metric multidimensional scaling analysis for the advertisement and territorial calls of Ischnocnema henselii. $\bullet=$ advertisement call and $\square=$ territorial call.

apresentada por Kwet \& Solé (2005) para as localidades brasileiras de São Francisco de Paula (RS) e Ilha de Santa Catarina (SC) e, as das localidades presentemente estudadas, decorrem de diferenças na interpretação da estrutura do canto, confirmando assim a identidade de I. henselii em todas as populações analisadas.

Dendropsophus anceps (A. Lutz, 1929) - Figura 1b

Comentários taxonômicos. Dendropsophus anceps atualmente pertence ao grupo de Dendropsophus leucophyllatus que inclui

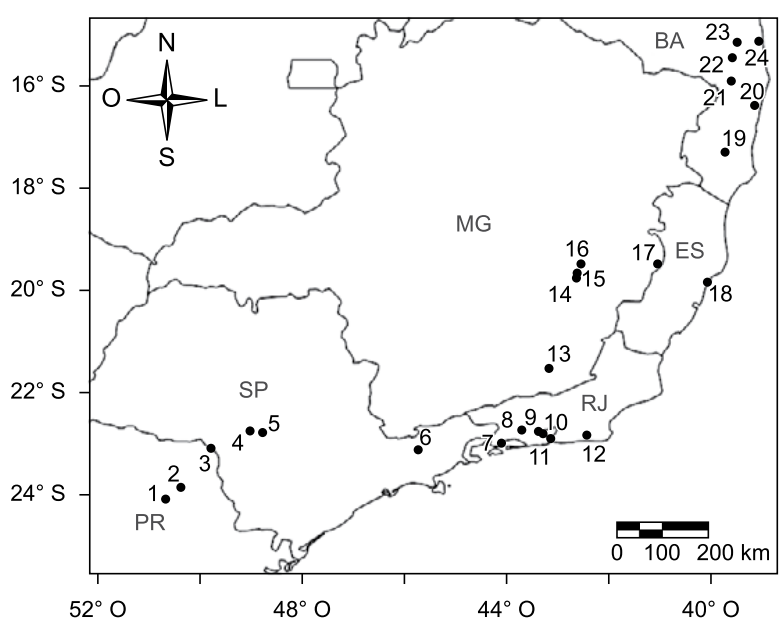

Figura 5. Mapa atualizado da distribuição geográfica de Dendropsophus anceps. 1.Telêmaco Borba, 2. Ibaiti e Figueira, 3. Ribeirão Claro, 4. Borebi, 5. Lençóis Paulista, 6. Caçapava, 7. Mangatiba, 8. Seropédica, 9. Duque de Caxias, 10. Belford Roxo, 11. Rio de Janeiro, 12. Saquarema, 13. Rio Novo, 14. Parque Estadual do Rio Doce, 15. Marliéia, 16. Ipatinga, 17. Aimorés, 18. Barra do Sahy, 19. Teixeira de Freitas, 20. Porto Seguro, 21. Itapebi, 22. Pau Brasil, 23. Jussari e 24. Una. Dados extraídos de: 1. Machado \& Haddad (2001); 2. Presente estudo; 3. Conte et al. (2009); 4 e 5. Rolim et al. (2008); 6. Gomes \& Martins (2006); 7. Carvalho-e-Silva et al. (2008); 8. Lutz (1973); 9. Lutz (1929); 10. Cochran (1955); 11. Lutz (1954), 12. Wogel et al. (2000); 13. Feio \& Ferreira (2005); 14. Feio et al. (1998); 15-17. Nascimento \& Feio (1999); 18. Haddad et al. (1995); 19-21, 23 e 25. Silvano \& Pimenta (2003) e 22. Argôlo (2000).

Figure 5. Map of the current geographic distribution of Dendropsophus anceps: 1.Telêmaco Borba, 2. Ibaito and Figueira, 3. Ribeirão Claro, 4. Borebi, 5. Lençóis Paulista, 6. Caçapava, 7. Mangatiba, 8. Seropédica, 9. Duque de Caxias, 10. Belford Roxo, 11. Rio de Janeiro, 12. Saquarema, 13. Rio Novo, 14. Parque Estadual do Rio Doce, 15. Marliéia, 16. Ipatinga, 17. Aimorés, 18. Barra do Sahy, 19. Teixeira de Freitas, 20. Porto Seguro, 21. Itapebi, 22. Pau Brasil, 23. Jussari, and 24. Una. Data from: 1. Machado \& Haddad (2001); 2. Present study; 3. Conte et al. (2009); 4 and 5. Rolim et al. (2008); 6. Gomes \& Martins (2006); 7. Carvalho-e-Silva et al. (2008); 8. Lutz (1973); 9. Lutz (1929); 10. Cochran (1955); 11. Lutz (1954); 12. Wogel et al. (2000); 13. Feio \& Ferreira (2005); 14. Feio et al. (1998); 15-17. Nascimento \& Feio (1999); 18. Haddad et al. (1995); 19-21, 23 and 25. Silvano \& Pimenta (2003); and 22. Argôlo (2000). 
oito espécies (Faivovich et al. 2005). Foi descrita por A. Lutz (1929) com o nome de "Hyla anceps", com base em indivíduos coletados em Duque de Caxias, município do Rio de Janeiro.

Comprimento rostro-cloacal. Foram medidos oito machos provenientes do Paraná (Anexo 1) que apresentaram $\mathrm{CRC}=39,44 \pm 1,34 \mathrm{~mm}(36,20-42,79 \mathrm{~mm})$. Essa variação de tamanho está contida na registrada por Lutz (1973). Apenas uma fêmea foi medida e apresentou CRC de 44,40 mm.

Distribuição geográfica. Até 1973 poucas localidades de ocorrência eram conhecidas, com apenas quatro registros no Estado do Rio de Janeiro (A. Lutz 1929, B. Lutz 1954, 1973, Cochran 1955). Entretanto, nos últimos anos, no período de 1995 a 2009, foram feitos 19 novos registros: um no Espírito Santo (Haddad et al. 1995), cinco em Minas Gerais (Feio et al. 1998, Nascimento \& Feio 1999, Feio \& Ferreira 2005), seis na Bahia (Argôlo 2000, Silvano \& Pimenta 2003), dois no Rio de Janeiro (Wogel et al. 2000, Carvalho-e-Silva et al. 2008), três em São Paulo (Gomes \& Martins 2006, Rolim et al. 2008) e dois no Paraná (Machado \& Haddad 2001, Conte et al. 2009) (Figura 5).

Novos registros. Duas novas populações de $D$. anceps foram registradas no Estado do Paraná, nos municípios de Ibaiti e Figueira. Em Ibaiti a espécie foi registrada em um açude com taboal $(120 \times 60 \mathrm{~m})$ localizado em matriz de pastagem, distante $20 \mathrm{~m}$ da mata ciliar do Rio Figueira (divisa dos municípios de Ibaiti e Figueira). No momento do registro foi possível observar 12 e 16 machos em atividade de vocalização nos meses de fevereiro e novembro de 2009, respectivamente. Já no município de Figueira a espécie foi registrada em um açude com densa vegetação aquática $(45 \times 30 \mathrm{~m})$ localizado em matriz de pastagem, distante $2.500 \mathrm{~m}$ do rio Figueira. No momento do registro foi possível observar 3 e 8 machos em atividade de vocalização nos meses de fevereiro e novembro, respectivamente, e apenas uma fêmea com óvulos conspícuos em fevereiro.
História natural. O conhecimento atual sobre a ecologia de D. anceps é diferente do panorama encontrado em 2004, ano em que foi publicado o livro vermelho de espécies ameaçadas de extinção no Estado do Paraná (Mikich \& Bérnils 2004). Na época, a espécie foi classificada como criticamente ameaçada, pois a única população até então conhecida, havia sido encontrada em um brejo com taboal em área aberta, cercado por plantios de espécies exóticas, estradas e linhas de transmissão (Segalla \& Langone 2004). Sabe-se, porém, que as diversas populações de D. anceps ocorrem em áreas abertas, tanto em açudes e brejos com taboais (Lutz 1973, Machado \& Haddad 2001, Gomes \& Martins 2006, Conte et al. 2009), quanto em açudes com vegetação herbácea/arbustiva marginal (Rolim et al. 2008). Além disso, atualmente são conhecidas quatro populações no Paraná, as quais ocorrem em ambientes alterados por ações humanas como poças em monoculturas, e taboais que sofrem influência de usinas hidrelétricas e termoelétricas.

Análise do canto. Foram registrados os cantos de anúncio e territorial de dois exemplares provenientes de Ribeirão Claro e Telêmaco Borba, Estado do Paraná. Ambos são formados por uma nota introdutória seguida por um número variável de notas secundárias (Figuras 6a-h), apresentando duas faixas de frequências, $\mathrm{H} 1$ entre 1.100 a $2.000 \mathrm{~Hz}$ e H2 entre 2.200 a $3.500 \mathrm{~Hz}$.

O canto de anúncio tem duração aproximada de 1,0 s, sendo constituído por uma nota introdutória pulsionada, seguida por uma série de aproximadamente seis notas secundárias pulsionadas. Em algumas ocasiões, a nota introdutória pode estar ausente ou duplicada. Em 94\% ( $\mathrm{n}=17)$ das notas introdutórias analisadas, a frequência dominante está situada no primeiro harmônico (H1), aparecendo no segundo harmônico em apenas 6\% $(n=1)$ das notas. Já o canto territorial tem duração de aproximadamente $1,4 \mathrm{~s}$, sendo formado por uma nota introdutória pulsionada com uma leve modulação de frequência ascendente, seguida por uma série de aproximadamente sete notas secundárias pulsionadas. Em 53\% (n=9) das notas introdutórias analisadas, a frequência

Tabela 3. Parâmetros bioacústicos do canto de anúncio e territorial de Dendropsophus anceps registrado em Ribeirão Claro e Telêmaco Borba, Paraná. Média \pm desvio padrão (amplitude); número de notas analisadas/número de indivíduos.

Table 3. Bioacoustic parameters of the advertisement call and territorial call of Dendropsophus anceps recorded in Ribeirão Claro and Telêmaco Borba, Paraná. Mean \pm standard deviation (range); number notes analyzed / number of individuals.

\begin{tabular}{llcc}
\hline & \multicolumn{1}{c}{ Parâmetros } & Canto de anúncio & Canto territorial \\
\hline Nota introdutória & Duração do canto & $1,06 \pm 0,32(0,74-1,88) ; 12 / 2$ & $1,42 \pm 0,29(0,82-2) ; 17 / 2$ \\
& H1- Frequência mínima & $1.263,4 \pm 32,4(1.200-1.329) ; 17 / 2$ & $1.276,6 \pm 50,8(1.200-1.373) ; 8 / 2$ \\
& H1- Frequência máxima & $1.961,4 \pm 95,3(1.710-2.074) ; 17 / 2$ & $1.705,4 \pm 71,1(1.573-1.855) ; 8 / 2$ \\
& H1-Frequência dominante & $1.526 \pm 24,9(1.453,1-1565,4) ; 17 / 2$ & $1.452,3 \pm 53,3(1.320,4-1.473) ; 8 / 2$ \\
& H2- Frequência mínima & $2.468 \pm 44,9(2.346-2.544) ; 17 / 2$ & $2.413,4 \pm 77,4(2.237-2.574) ; 8 / 2$ \\
& H2- Frequência máxima & $3.466,6 \pm 104,3(3.274-3584) ; 17 / 2$ & $2.413,4 \pm 77,4(2.237-2.574) ; 8 / 2$ \\
& H2- Frequência dominante & $2.829,2 ; 1 / 1$ & - \\
Duração da nota & $0,16 \pm 0,04(0,12-0,29) ; 17 / 2$ & $0,27 \pm 0,05(0,11-0,354) ; 8 / 2$ \\
& Número de pulsos por nota & $11,82 \pm 1,78(8-15), 17 / 2$ & $14,05 \pm 2,5(10-22) ; 24 / 2$ \\
& H1- Frequência mínima & $1.212,8 \pm 35,2(1.127-1255) ; 30 / 2$ & $1.251,2 \pm 37,1(1.182-1.309) ; 30 / 2$ \\
& H1- Frequência máxima & $2.000 \pm 46,3(1.928-2110) ; 30 / 2$ & $1.991,6 \pm 52,4(1.873-2.074) ; 30 / 2$ \\
& H1-Frequência dominante & $1.555 \pm 23,4(1.497,4-1.574,4) ; 30 / 2$ & $1.546 \pm 21(1.487,3-1.575,9) ; 27 / 2$ \\
& H2- Frequência mínima & $2.410 \pm 73,7(2.219-2.492) ; 30 / 2$ & $2.472 \pm 74,7(2.310-2.583) ; 30 / 2$ \\
& H2- Frequência máxima & $3.463,7 \pm 36,2(3.383-3.511), 30 / 2$ & $3.446,9 \pm 47,6(3.347-3529) ; 30 / 2$ \\
H2- Frequência dominante & & - & $2.842 \pm 18,4(2.827,7-2.862,9) ; 3 / 1$ \\
& Duração da nota & $0,07 \pm 0,007(0,06-0,09) ; 30 / 2$ & $0,06 \pm 0,006(0,058-0,08) ; 30 / 2$ \\
& Número de pulsos por nota & $5,4 \pm 0,85(4-7) ; 30 / 2$ & $4,7 \pm 0,9(4-7) ; 30 / 2$ \\
\hline
\end{tabular}



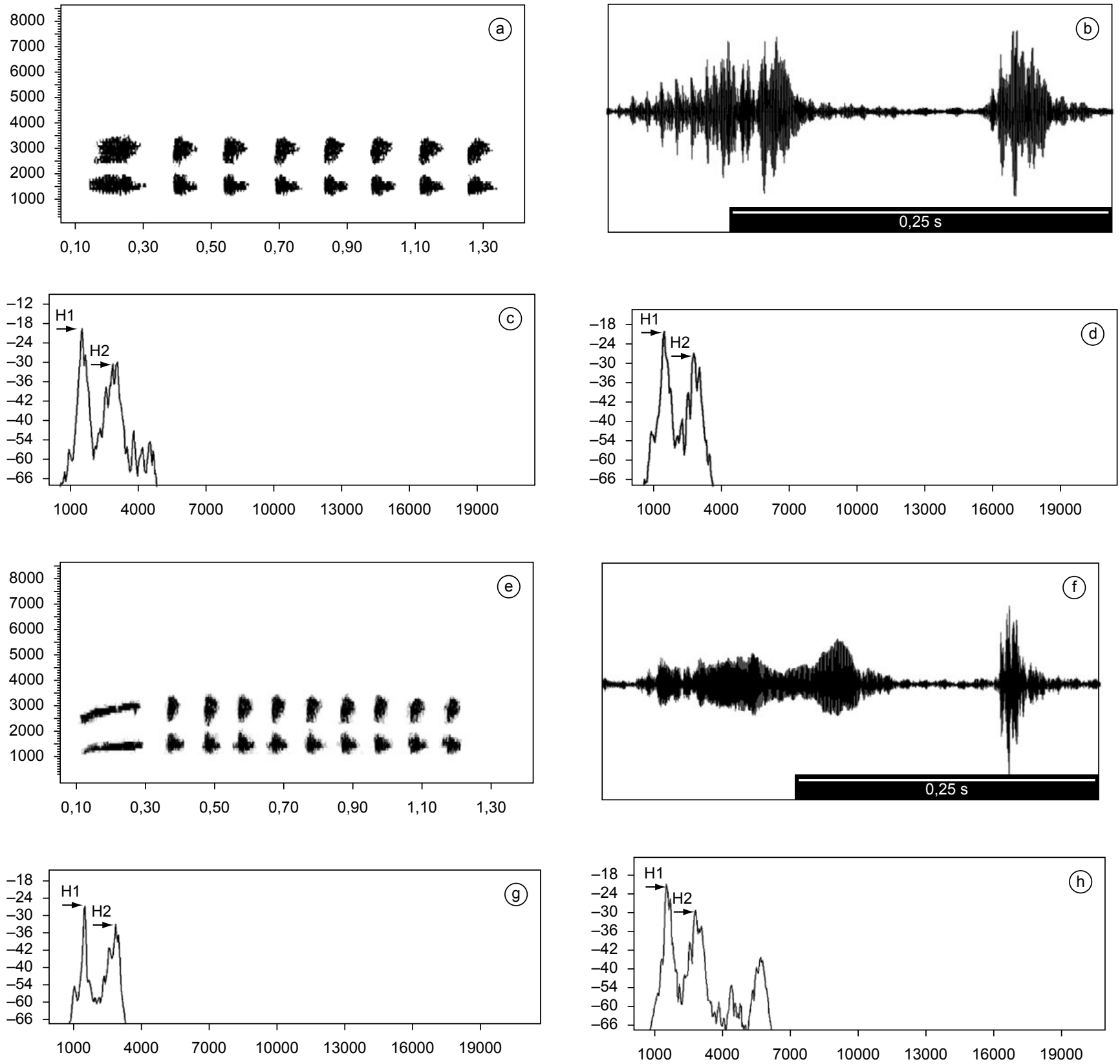

Figura 6. Canto de Dendropsophus anceps. a) Sonograma e b) Osciligrama da nota introdutória e nota secundária do canto de anúncio; c) Espectro de potência da nota introdutória e d) Espectro de potência da nota secundária do canto de anúncio; e) Sonograma e f) Oscilograma das notas introdutória e secundária do canto territorial; g) Espectro de potência da nota introdutória e h) Espectro de potência da nota secundária do canto territorial. Ribeirão Claro, Paraná. Temperatura do ar: $17^{\circ} \mathrm{C}$. Umidade relativa do ar: $82 \%$.

Figure 6. Call of Dendropsophus anceps. a) Sonogram and b) Oscilogram of the introductory note and secondary note of the advertisement call, c) Power spectrum of the introdutory note; d) Power spectrum of the secundary note; e) Sonogram and f) Oscilogram of the introductory notes and secondary notes of territorial call; g) power spectrum of the note and H-power spectrum of the secondary note of the territorial call. Ribeirão Claro, Paraná state. Air temperature: $17{ }^{\circ} \mathrm{C}$. Relative air humidity: $82 \%$.

dominante aparece no segundo harmônico (H2) e em 47\% (n=8) no primeiro harmônico (H1) (Tabela 3).

As variáveis utilizadas para comparação entre as notas introdutórias e secundárias dos cantos de anúncio e territorial diferiram da distribuição normal (Homogeneidade de variância $=26,77, \mathrm{gl}=84, \mathrm{p}<0,0001 ;$ kurtosis $=88,02$; $\mathrm{p}<0,0001$; teste geral de Doornik \& Hansen $=227,9 ; \mathrm{p}<0,0001$ ), e ambas diferiram entre si quanto à sua estrutura (ANOSIM: $\mathrm{R}=0,4648 ; \mathrm{p}<0,0001 ;$ Figura 7; Tabela 4).
Não foram encontrados os harmônicos H3 e H4 descritos por Gomes \& Martins (2006). Além disso, foram registradas outras diferenças em alguns dos parâmetros analisados: 1) a nota introdutória do canto de anúncio foi mais longa, 0,004 s, com menor amplitude de frequência, em torno de 1.200 a 3.440 (1500-3900 Hz - Gomes \& Martins 2006); 2) Gomes e Martins (2006) consideraram a nota introdutória do canto territorial de $D$. anceps como multipulsionada possivelmente por não conseguirem identificar unidades discretas da nota 


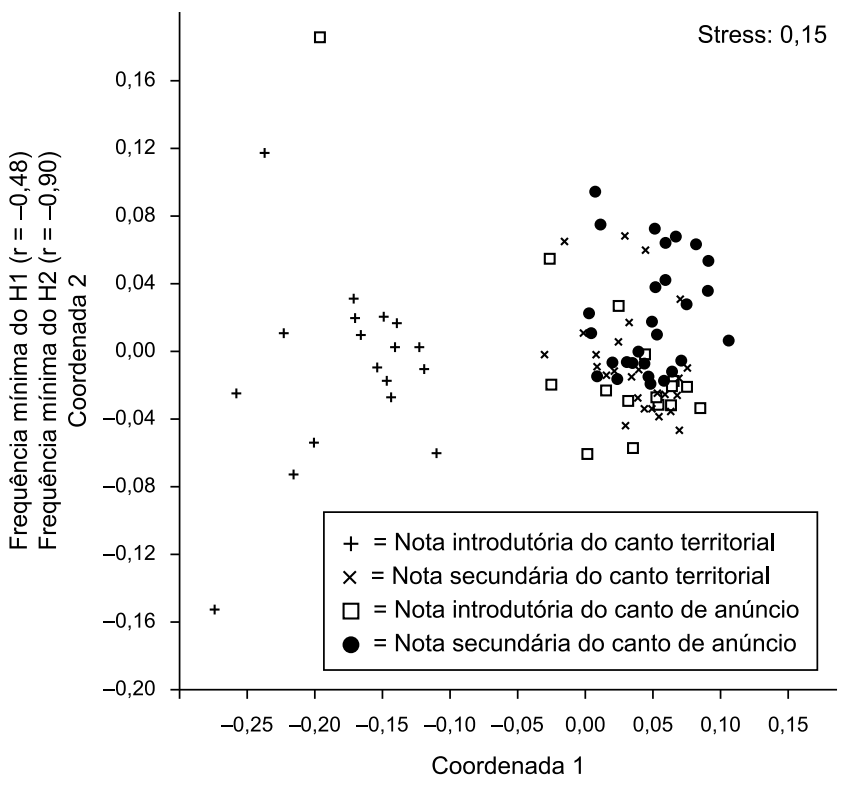

Duração da nota $(r=-0,81) \quad$ Frequência máxima do $\mathrm{H} 1(\mathrm{r}=0,96)$ Número de pulsos $(r=-0,69) \quad$ Frequência máxima do $\mathrm{H} 2(r=0,73)$ Frequência dominante do $\mathrm{H} 1(r=0,53)$

Figura 7. Análise escalonada multidimensional não-métrica para as notas territoriais introdutórias, territoriais secundárias, de anúncio introdutórias e de anúncio secundárias de Dendropsophus anceps.

Figure 7. Non-metric multidimensional scaling analysis for the introductory and secondary notes of the territorial call and the introductory and secondary notes of the advertisement call of Dendropsophus anceps.

Tabela 4. Valores de R para o teste a-posteriori da ANOSIM entre as notas introdutórias territoriais e de anúncio e entre as notas secundárias territoriais e de anúncio do canto de Dendropsophus anceps.

Table 4. Values of R for the a-posteriori test of ANOSIM between the introductory notes of the territorial and advertisement calls and between the secondary notes of the territorial and the advertisement calls of Dendropsophus anceps.

\begin{tabular}{lcll}
\hline & $\begin{array}{c}\text { Introdutória } \\
\text { de anúncio }\end{array}$ & $\begin{array}{c}\text { Secundária } \\
\text { territorial }\end{array}$ & $\begin{array}{c}\text { Secundária } \\
\text { de anúncio }\end{array}$ \\
\hline Introdutória territorial & $0,7941(0)$ & $0,9561(0)$ & $0,9741(0)$ \\
Introdutória de anúncio & - & $0,1641(0,0058)$ & $0,3338(0)$ \\
Secundária territorial & - & - & $0,1006(0,008)$ \\
\hline
\end{tabular}

no oscilograma ou sonograma. No presente estudo, a nota introdutória do canto territorial foi considerada pulsionada, sendo possível identificar unidades discretas formando a nota no sonograma; 3) a frequência dominante foi localizada no H1, em torno de $1.500 \mathrm{~Hz}$, em $94 \%$ das notas analisadas, enquanto que em todos os cantos analisados por Gomes \& Martins (2006) a frequência dominante foi localizada na $\mathrm{H} 2$, em torno de $3.200 \mathrm{~Hz}$. A mesma diferença aparece na comparação entre os cantos territoriais, sendo que nos cantos de populações do Paraná, a frequência dominante está em torno de $1.500 \mathrm{~Hz}$, enquanto que nos cantos analisados por Gomes \& Martins (2006) está em torno de $3.100 \mathrm{~Hz}$. Na análise do canto territorial, apresentada por Bokermann (1967), a frequência dominante da nota introdutória está em torno de $1.500 \mathrm{~Hz}$, valor muito similar ao encontrado nos cantos registrados no Paraná.
Existem evidências de que, em determinadas situações sociais, os machos podem alterar as características espectrais do canto. Por exemplo, em algumas espécies os machos podem aumentar ou diminuir a frequência dominante do canto territorial durante interações agonísticas de competição (Lopez et al. 1988, Bee et al. 1999, 2000, Bee \& Bowling 2002). Também é possível que machos possam ajustar a frequência fundamental do canto de anúncio em função da amplitude do espectro de frequência que é poluído por ruído ambiental (Nomura 2008). Entre as guildas estabelecidas em função das características espectrais do canto de anúncio, as espécies de banda larga (i.e., espécies cujo canto de anúncio ocupa uma ampla faixa do espectro de frequência, sensu Nomura 2008) podem ser mais aptas a este tipo de ajuste que espécies que são mais especializadas no uso do espaço acústico.

Dendropsophus nahdereri (B. Lutz \& Bokermann, 1963) Figura 1c.

Comentários taxonômicos. Dendropsophus nahdereri pertence ao grupo de Dendropsophus marmoratus que inclui oito espécies (Faivovich et al. 2005). Foi descrita por Lutz \& Bokermann (1963) como "Hyla nahdereri", com base em exemplares coletados em São Bento do Sul, Santa Catarina.

Comprimento rostro-cloacal. Foram medidos 12 machos e apenas uma fêmea (Anexo 1): os machos apresentaram $\mathrm{CRC}=42,9 \pm 1,71 \mathrm{~mm}(39,3-45,1 \mathrm{~mm})$, variação de tamanho semelhante às apresentadas por Lutz (1973). A fêmea apresentou $\mathrm{CRC}=50,5 \mathrm{~mm}$

Distribuição geográfica. Apresenta distribuição restrita aos Estados de Santa Catarina e Paraná (Garcia \& Vinciprova 1998, Haddad et al. 2008), sendo poucos os registros publicados (Peixoto \& Gomes 1999, Ghizoni et al. 2000, Machado \& Conte 2001, Conte \& Rossa-Feres 2006).

Novos registros. Neste estudo, duas novas populações de D. nahdereri foram registradas, uma em Vargem Bonita, Santa Catarina e outra em General Carneiro, Paraná, sendo esta a segunda população encontrada no estado. Garcia et al. (2007) consideram a área de ocorrência de $D$. nahdereri somente para Floresta Ombrófila Densa, mas os registros atuais indicam que a distribuição se concentra mais em Floresta Ombrófila Mista (Figura 8).

História natural. Nas populações observadas neste estudo, os machos de $D$. nahdereri vocalizaram no período da tarde, no interior de floresta, sempre no alto de árvores, abrigados em frestas e interior de bromélias, a partir de agosto até meados de novembro. No crepúsculo vespertino, foram observados machos se deslocando para corpos d'água temporários, tanto na borda quanto no interior dos remanescentes florestais amostrados, utilizando como poleiros galhos e frestas em árvores e, eventualmente, vocalizando diretamente no solo. Suas vocalizações são de intensidade bastante alta, podendo ser ouvidas a longas distâncias. Girinos foram registrados nos meses de janeiro, setembro e dezembro de 2007.

Análise do canto. Foi registrado o canto de anúncio de dois exemplares no município de São José dos Pinhais, Estado do Paraná, o qual apresentou uma estrutura pulsionada, com duas faixas de frequência: $\mathrm{H} 1$ entre 900 e $1.800 \mathrm{~Hz}$ e H2 entre 2.000 e $3.300 \mathrm{~Hz}$, com frequência dominante localizada no segundo harmônico (Figuras 9a-9c). Em alguns cantos os pulsos estão justapostos, dificultando sua distinção e, ocasionalmente ocorre a formação de grupos de pulsos, principalmente no final do canto, semelhante ao registrado por Orrico et al. (2009) (Tabela 5). Apesar disso, a frequência dominante dos exemplares gravados 


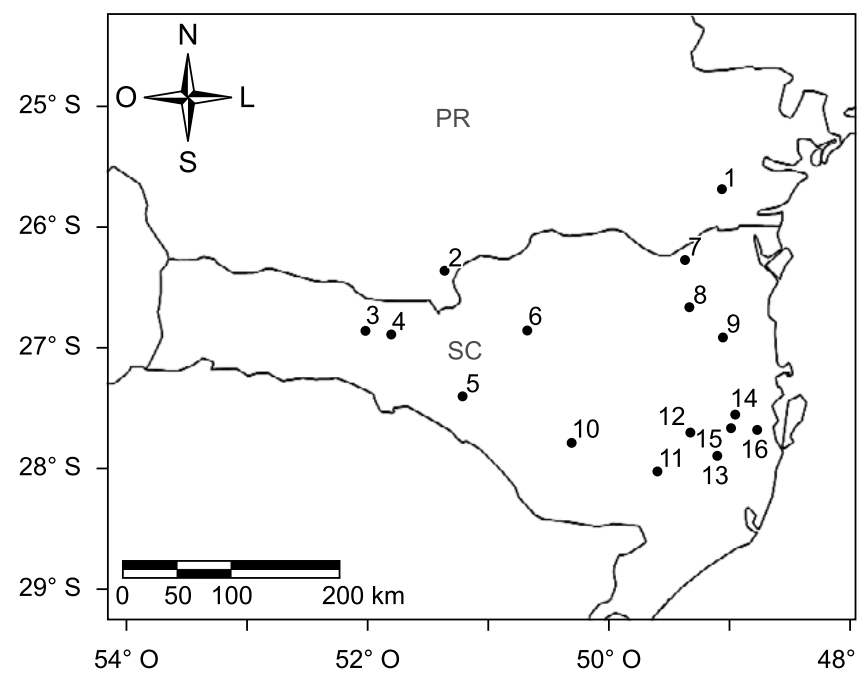

Figura 8. Mapa atualizado da distribuição geográfica de Dendropsophus nahdereri. 1. São José dos Pinhais, 2. General Carneiro, 3. PARNA das Araucárias, 4. Vargem Bonita, 5. Campos Novos, 6. Lebon Régis, 7. São Bento do Sul, 8. Rio dos Cedros, 9. Blumenau, 10. Lages, 11. Urubici, 12. Alfredo Wagner, 13. Anitápolis, 14. Angelina, 15. Rancho Queimado e 16. Santo Amaro da Imperatriz. Dados extraídos de: 1. Machado \& Conte (2001); 2 e 4. Presente estudo; 3,5,9,10,11,12 e 13. Lucas (2008); 6. Lingnau (2008); 8. Ghizoni et al. (2000); 7. Coleção MZUSP e 16. Coleção CFBH.

Figure 8. Map of the current geographic distribution of Dendropsophus nahdereri. 1. São José dos Pinhais, 2. General Carneiro, 3. Parque Nacional das Araucárias, 4. Vargem Bonita, 5. Campos Novos, 6. Lebon Régis, 7. São Bento do Sul, 8. Rio dos Cedros, 9. Blumenau, 10. Lages, 11. Urubici, 12. Alfredo Wagner, 13. Anitápolis, 14. Angelina, 15. Rancho Queimado and 16. Santo Amaro da Imperatriz. Data from: 1. Machado \& Conte (2001); 2 and 4. Present study estudo; 3,5,9,10,11,12 e 13. Lucas (2008); 6. Lingnau (2008); 8. Ghizoni et al. (2000); 7. MZUSP collection and 16. CFBH collection.
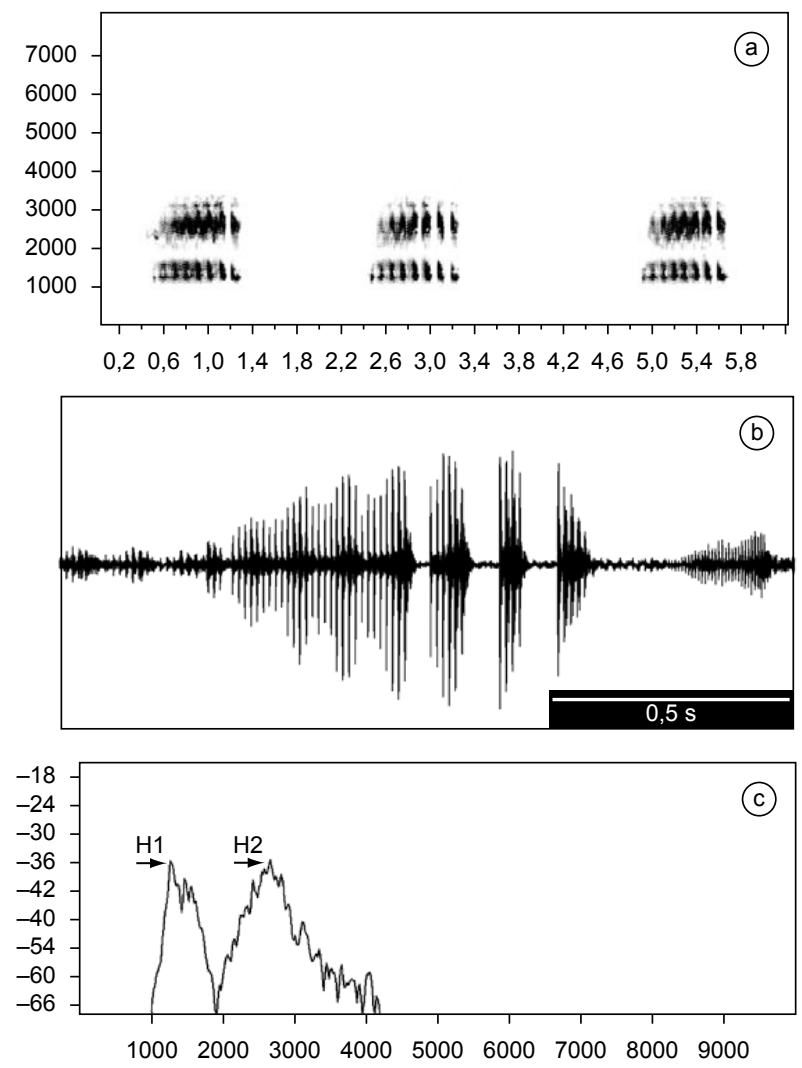

Figura 9. Canto de anúncio de D. nahdereri. a) Sonograma (três cantos), b) Oscilograma e c) espectro de potência (um canto). São José dos Pinhais, Paraná. Temperatura do ar: $14{ }^{\circ} \mathrm{C}$. Umidade relativa do ar: $85 \%$.

Figure 9. Advertisement call of D. nahdereri. a) Sonogram (three calls), b) Oscilogram and c) Power spectrum (one call). São José dos Pinhais State. Air temperature: $14^{\circ} \mathrm{C}$. Relative air humidity: $85 \%$.

Tabela 5. Parâmetros bioacústicos do canto de anúncio de Dendropsophus nahdereri registrado em São José dos Pinhais, Paraná, e por Orrico et al. 2009 em Lebon Régis e Anitápolis, Santa Catarina. Média \pm desvio padrão (amplitude); número de notas analisadas/número de indivíduos.

Table 5. Bioacoustic parameters of the advertisement call and territorial call of Dendropsophus nahdereri, recorded in São José dos Pinhais, Paraná State, and by Orrico et al. (2009) at Lebon Régis and Anitápolis, Santa Catarina State. Mean \pm standard deviation (range); number of notes analyzed/ number of individuals.

\section{Parâmetros}

Canto de anúncio

\begin{tabular}{lcc}
\cline { 2 - 3 } & (Presente estudo) & (Orrico et al. 2009) \\
\hline H1 - Frequência mínima & $1.061,1 \pm 76,9(925,9-1137) ; 11 / 2$ & $1.018,3 \pm 69,6(895,2-1.169,5) ; 60 / 5$ \\
H1 - Frequência máxima & $1.770,6 \pm 45,9(1.688-1.828) ; 11 / 2$ & $1.814,2 \pm 84,5(1.625,5-1.949) ; 60 / 5$ \\
H2 - Frequência mínima & $2.129 \pm 75,7(2.025-2.283) ; 11 / 2$ & - \\
H2 - Frequência máxima & $3.244,9 \pm 75,1(3.086-3.375) ; 11 / 2$ & - \\
Frequência dominante & $2.587 \pm 109(2.396-2.691,1) ; 11 / 2$ & $1.392,4 \pm 27(1.378-1.464,3) ; 60 / 5$ \\
Duração da nota & $0,75 \pm 0,10(0,589-0,909) ; 11 / 2$ & $0,699 \pm 0,148(0,443-0,982) ; 60 / 5$ \\
Número de pulsos & $57 \pm 10(47-76) ; 11 / 2$ & $48,1 \pm 8,2(31-66) ; 60 / 5$ \\
Taxa de repetição (notas/s) & $1,29 \pm 0,3(0,9-1,7) ; 5 / 2$ & - \\
\hline
\end{tabular}

em São José dos Pinhais, Paraná difere da descrição de Orrico et al. (2009), para populações de Lebon Régis e Anitápolis, Santa Catarina, que consideraram o primeiro harmônico dominante. Nos espécimes de São José dos Pinhais, o segundo harmônico concentra a maior parte da energia do canto. Tais diferenças podem decorrer da dificuldade de interpretação que acontece quando a energia em dois harmônicos é muito semelhante, tornando-se difícil discernir qual dos harmônicos representa a frequência dominante (Lingnau et al. 2008).

Pseudis cardosoi Kwet (2000) - Figura 1d.

Comentários taxonômicos. Pseudis cardosoi foi descrito por Kwet (2000) a partir de exemplares coletados em São Francisco de Paula, Rio Grande do Sul, havendo poucos registros 


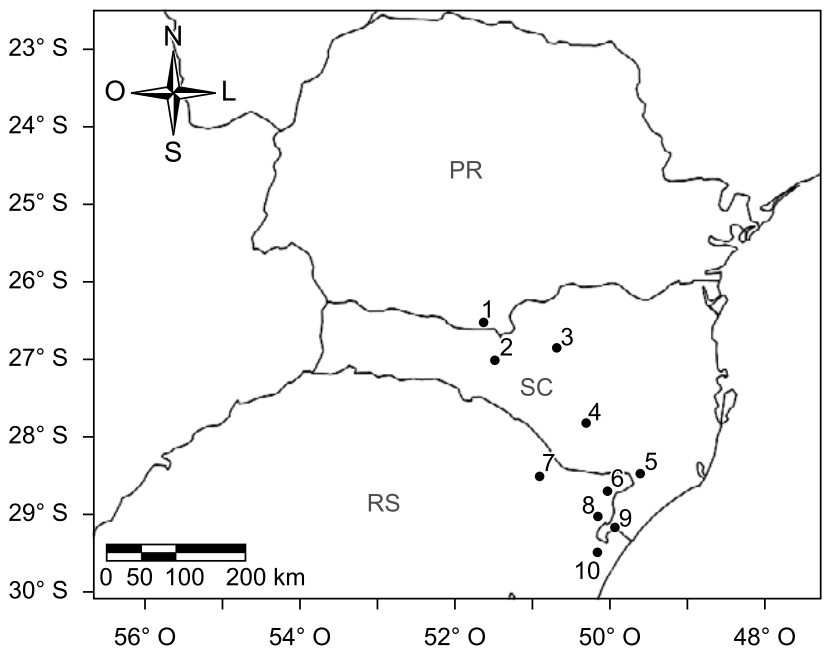

Figura 10. Mapa atualizado da distribuição geográfica de Pseudis cardosoi. 1. Palmas, 2. Água Doce, 3. Lebon Régis, 4. Lages, 5. Bom Jardim da Serra, 6. São José dos Ausentes, 7. Vacaria, 8. Cambará do Sul, 9. Praia Grande e 10. São Francisco de Paula. Dados extraídos de: 1. Presente estudo; 2,4 e 9. Lucas (2008); 3. Lingnau \& Di-Bernardo (2006); 7, 8 e 10. Kwet (2000); 5. Coleções CFBH e MZUSP e 6. Coleção MCP.

Figure 10. Map of the current geographic distribution of Pseudis cardosoi. 1. Refúgio da Vida Silvestre dos Campos de Palmas, 2. Água Doce, 3. Lebon Régis, 4. Lages, 5. Bom Jardim da Serra, 6. São José dos Ausentes, 7. Vacaria, 8. Cambará do Sul, 9. Praia Grande and 10. São Francisco de Paula. Date from: 1. Present study; 2,4 and 9. Lucas (2008); 3. Lingnau \& Di-Bernardo (2006); 7, 8 and 10. Kwet (2000); 5. CFBH and MZUSP collections and 6. MCP collection.

além da localidade tipo (e.g. Lingnau \& Di-Bernardo 2006, Lucas 2008).

Comprimento rostro-cloacal. Foram coletados quatro machos e apenas uma fêmea (Anexo 1): os machos apresentaram $\mathrm{CRC}=41,80 \pm 2,56 \mathrm{~mm}(38-44.60 \mathrm{~mm})$. Essa variação de tamanho está contida na registrada por Kwet (2000). A fêmea apresentou $\mathrm{CRC}=53,90 \mathrm{~mm}$.

Distribuição geográfica. Além das localidades citadas na descrição da espécie, existe o registro para Lebon Régis (Lingnau \& Di-Bernardo 2006), e registros para outras quatro localidades no Estado de Santa Catarina e três no Rio Grande do Sul foram obtidos em museus (Figura 10).

Novos registros. Neste estudo, o primeiro registro de Pseudis cardosoi para o Paraná provém do Refúgio da Vida Silvestre dos Campos de Palmas. A região é formada por campos naturais chamados Campos de Palmas que possuem uma delimitação nítida entre campo e capões de mata (Maack 1981). A população registrada no Estado do Paraná foi encontrada em uma unidade de conservação que é formada por terras particulares e não prevê desapropriação. Várias atividades antropogênicas colaboraram com a descaracterização dos campos e capões de mata da região, tais como agricultura, pecuária, exploração madeireira, queimadas (incluindo para renovação de pastagens) e a introdução de espécies exóticas de árvores como pinus e eucaliptos (Medeiros et al. 2005, Roderjan et al. 2002). Essas atividades provocam impactos negativos que são particularmente evidentes em ecossistemas de campo, com a redução da vazão e do lençol freático (GISP 2005), podendo afetar a dinâmica dos corpos d'água encontrados na região.

História natural. Foram registrados adultos de Pseudis cardosoi em três corpos d'água temporários em área de campo, sendo que machos em atividade de vocalização foram observados de agosto a novembro de 2009 . Os machos vocalizavam flutuando na parte mais profunda dos corpos d'água, parcialmente submersos, geralmente apoiados em vegetação herbácea aquática, como as demais espécies do gênero (Rossa-Feres \& Jim 2001, Brandão et al. 2003, Zank et al. 2008).

Análise do canto. Foi registrada a vocalização de três indivíduos, sendo identificados dois tipos de canto: de anúncio (sensu Wells 1977) e territorial (sensu Littlejohn 2001) (Figuras 11a-f). Ambos são compostos por notas pulsionadas, sendo que o canto de anúncio é emitido em série e o territorial é emitido de modo intermitente entre os cantos de anúncio. O canto de anúncio tem duração aproximada de $0,15 \mathrm{~s}$, sendo constituído por uma série de aproximadamente 11 notas com frequência dominante em torno de $1.700 \mathrm{~Hz}$. Já o canto territorial tem duração aproximada de $0,04 \mathrm{~s}$, sendo constituído por uma série de aproximadamente cinco notas com frequência dominante em torno de $1.100 \mathrm{~Hz}$. O canto territorial foi observado somente quando o coro de machos era superior a 50 indivíduos. Os cantos territorial e de anúncio (Tabela 6) não diferiram da distribuição normal (homogeneidade de variância $=12,18 ; \mathrm{GL}=35, \mathrm{p}=0,7768$; kurtosis $=27,57$; $\mathrm{p}=0,10$; Doornik \& Hansen $=8,323, \mathrm{p}=0,60)$ e diferiram quanto à sua estrutura (MANOVA: Pillai trace $=0,97$; df $1=4$; df $2=9, \mathrm{~F}=80,55, \mathrm{p}<0,0001)$. A análise de covariância permitiu identificar quais aspectos estruturais (espectrais ou temporais) são modulados para a produção de cantos territoriais e de anúncio (Figura 12). Assim os cantos territorial e de anúncio diferem principalmente em função da frequência máxima, frequência mínima e número de pulsos. Os dois tipos de canto diferem pouco em relação à frequência dominante, que se comportou como uma co-variável da frequência mínima, por isso foi removida da análise. Usualmente, a comunicação multimodal é definida como a exibição complexa de diversos componentes, que contêm sinais ou elementos de diferentes modalidades sensoriais, como químicas, visuais ou mecânicas (Partan \& Marler 1999, 2005, Candolin 2003, Hebets \& Papaj 2005). Estudos recentes de comunicação multimodal têm procurado responder se a "mensagem" transmitida pelos diferentes modos de sinalização representa informações redundantes ou distintas (Hebets \& Papaj 2005, Partan \& Marler 2005). As diferenças encontradas entre os cantos territorial e de anúncio de $P$. cardosoi permitem uma nova interpretação para a comunicação multimodal: sinais complexos, como a vocalização de anfíbios, podem transmitir mais de uma mensagem entre o emissor e o receptor. Por exemplo, o canto de anúncio de $P$. cardosoi representa um sistema redundante de comunicação "multimodal", uma vez que é composto apenas por sinais acústicos, fornecendo informações utilizadas pelas fêmeas para avaliar tanto o tamanho quanto a condição reprodutiva dos machos (Wells 2007). Por outro lado, o canto territorial apresenta variação nas frequências mínimas e máximas e no número de pulsos, mas não na frequência dominante. Em anfíbios, a frequência dominante do canto de anúncio é considerada como a principal característica utilizada pelas fêmeas para seleção do parceiro sexual (Wells 2007). Desta maneira, a variação nos componentes do canto territorial carrega informação destinada às interações agonísticas, enquanto que a frequência dominante fornece informações destinadas à reprodução, representando assim um sistema que transmite informações distintas de comunicação "multimodal". 

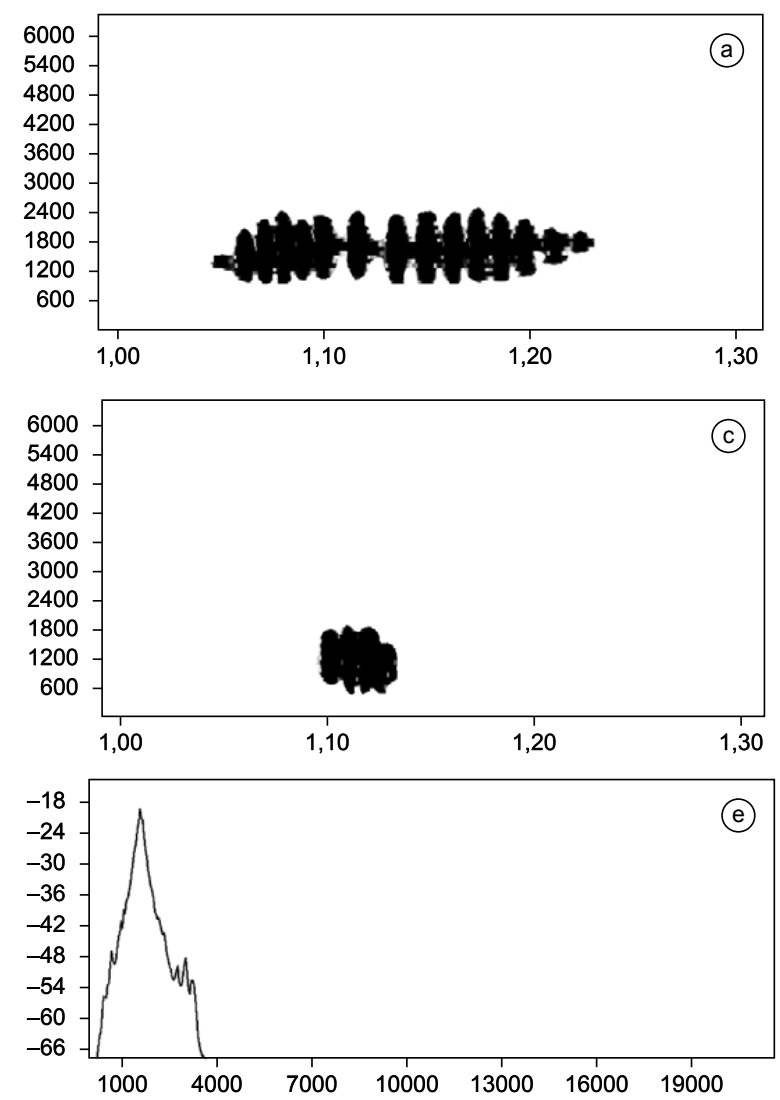
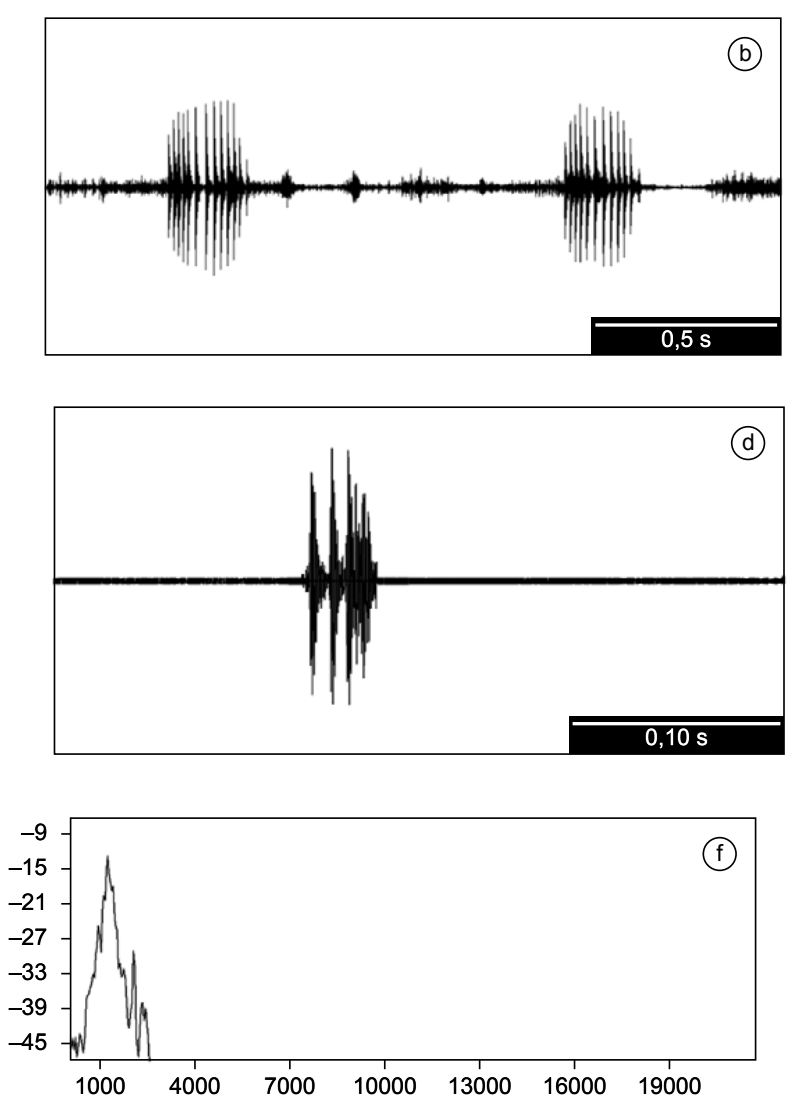

Figura 11. Canto de Pseudis cardosoi. a) Sonograma (um canto) e b) Oscilograma do canto de anúncio (dois cantos); c) sonograma e d) Oscilograma do canto territorial; e) espectro de potência do canto de anúncio e f) espectro de potencia do canto territorial. REVS dos Campos de Palmas, Paraná. Temperatura do ar: $14{ }^{\circ} \mathrm{C}$. Umidade relativa do ar: $85 \%$.

Figure 11. Call of Pseudis cardosoi. a) Sonogram (one call) and b) Oscilogram of the advertisement call (two calls); c) Sonogram and d) Oscilogram of the territorial call; e) Power spectrum of the advertisement call and f) Power spectrum of the territorial call. Refúgio da Vida Silvestre dos Campos de Palmas, Paraná state. Air temperature: $14^{\circ} \mathrm{C}$. Relative air humidity: $85 \%$.

Tabela 6. Parâmetros bioacústicos do canto de Pseudis cardosoi registrado REVS dos Campos de Palmas, Paraná (Média \pm desvio padrão (amplitude); número de notas analisadas/número de indivíduos), e por Kwet (2000) em São Francisco de Paula, Rio Grande do Sul (temperatura do ar: 10/19 ${ }^{\circ} \mathrm{C}$ ).

Table 6. Bioacoustic parameters of the advertisement call and territorial call of Pseudis cardosoi, recorded in Refúgio da Vida Silvestre dos Campos de Palmas, Paraná State (Mean \pm standard deviation (range); number of notes analyzed /number of individuals), and by Kwet (2000) at São Francisco de Paula, Rio Grande do Sul State (air tempereture: $10 / 19^{\circ} \mathrm{C}$ ).

\begin{tabular}{lccc}
\hline \multicolumn{1}{c}{ Parâmetros } & \multicolumn{2}{c}{ Canto de anúncio } & Canto territorial \\
\cline { 2 - 4 } & \multicolumn{1}{c}{ (presente estudo) } & (Kwet 2000) & (presente estudo) \\
\hline Duração do canto & $0,15 \pm 0,01(0,131-0,186) ; 47 / 3$ & $0,23 / 0,38$ & $0,04 \pm 0,009(0,038-0,056) ; 7 / 1$ \\
Frequência mínima & $838,03 \pm 52,07(757,1-1.038) ; 47 / 3$ & - & $466,9 \pm 62,3(403,3-537,8) ; 7 / 1$ \\
Frequência máxima & $2.615,93 \pm 195,29(2.316-3.170) ; 47 / 3$ & - & $1.807 \pm 108,3(1.703-1.948) ; 7 / 1$ \\
Frequência dominante & $1.741,1 \pm 127,2(1.610,8-1.958,6) ; 47 / 3$ & $1.700-2.300 / 1.500-2.300$ & $1.137 \pm 298,3(794,2-1.703) ; 7 / 1$ \\
Número de notas por canto & $11,97 \pm 0,74(11-13) ; 47 / 3$ & $11-22 / 13-20$ & $5,14 \pm 2,03(3-7) ; 7 / 1$ \\
Taxa de repetição & $62,3 \pm 6(55,55-72,58) ; 10 / 3$ & $70-80 / 30-60$ & - \\
Intervalo entre as notas & $0,95 \pm 0,23(0,714-1,56) ; 47 / 3$ & - & - \\
\hline
\end{tabular}

O canto de anúncio analisado é muito similar ao descrito por Kwet (2000) na localidade tipo da espécie e todos os parâmetros estão contidos na variação registrada por esse autor. $\mathrm{O}$ canto territorial de $P$. cardosoi tem estrutura temporal similar aos cantos agressivos ou territoriais de Pseudis bolbodactylus e P. minutus (Vaz-Silva et al. 2007, Zank et al. 2008). Nas três espécies de Pseudis, os cantos agressivos ou territoriais são de duração mais curta que o canto de anúncio.
Scinax granulatus (Peters, 1871) - Figura 1e.

Comentários taxonômicos. Atualmente está alocada no clado de Scinax ruber, cujas espécies não estão associadas a um grupo especifico (Faivovich et al. 2005). Foi descrita por Peters (1871) como "Hyla eringiophila" com base em exemplares coletados em Porto Alegre, Rio Grande do Sul. Kwet (2001a) sinonimizou Scinax eringiophilus com $S$. granulatus através de comparações 


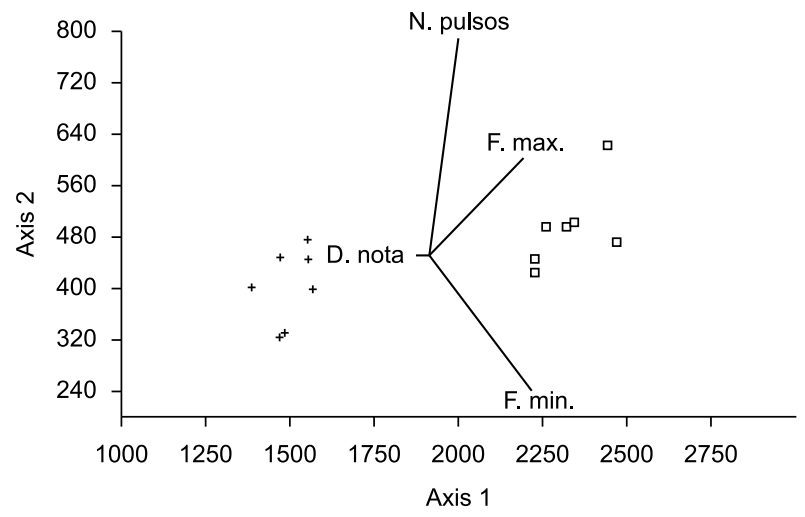

Figura 12. CVA scatter plot demonstrando os principais parâmetros que diferenciam os cantos de $P$. cardosoi. $+=$ canto territorial e $\square=$ canto de anúncio.

Figure 12. CVA scatter plot showing the main parameters that differentiate the calls of $P$. cardosoi $+=$ territorial call and $\square=$ advertisement call.

morfológicas entre o holótipo de S. granulatus (ZMB 7253) e exemplares recentemente coletados perto da localidade tipo (Bela Vista, província de Buenos Aires) e em vários municípios do Rio Grande do Sul (e.g. Candiota, Rio Grande, Caçapava do Sul, Porto Alegre, Viamão, Cambará do Sul, entre outras). Análises bioacústicas do canto de espécimes provenientes de diferentes localidades no Uruguai e no Rio Grande do Sul suportam a sinonímia (A. Kwet, com. pess.).

Comprimento rostro-cloacal. Foram medidos 26 machos (Anexo 1), que apresentaram $\mathrm{CRC}=33,54 \pm 1,59 \mathrm{~mm}$ (29,45-36,8 mm), medidas estas contidas dentro da variação registrada por Kwet (2001a, b).

Distribuição geográfica. Além da ocorrência na Argentina e Uruguai (Frost 2009), Scinax granulatus está amplamente distribuída no sul do Brasil, nos estados do Rio Grande do Sul e de Santa Catarina (Braun, P.C. \& Braun, C.A.S. 1980, Frost 2009), tendo apenas um registro no Estado do Paraná (Moresco et al. 2009).

Novos registros. Neste estudo, quatro novas populações foram identificadas, sendo duas no Estado do Paraná, no município de General Carneiro e no REVS dos campos de Palmas, e duas em Santa Catarina, no município de Vargem Bonita e no PARNA das Araucárias (Figura 13). A atual distribuição geográfica de S. granulatus difere da apresentada por Moresco et al. (2009), que considera apenas seis localidades de ocorrência dessa espécie no Brasil.

História natural. Adultos e girinos de $S$. granulatus foram registrados em diversos corpos d'água temporários em área aberta, na borda e no interior de remanescentes florestais. Machos em atividade de vocalização foram observados nos períodos de janeiro e fevereiro de 2007, e de agosto a dezembro de 2007. Girinos foram registrados ao longo de 2007 com exceção dos meses de junho e agosto. Foram registradas vocalizações nos abrigos diurnos no período da tarde, porém, o maior número de machos vocalizando foi registrado no entorno de corpos d'água, por volta das 21:00 h. Os machos vocalizavam empoleirados sobre galhos, troncos de vegetação arbórea e arbustiva, entre as folhas e talos de vegetação herbácea, em frestas de árvores ou rochas e diretamente no solo.

Análise do canto. Foram analisados cantos de quatro machos provenientes de General Carneiro e REVS dos Campos de Palmas, Paraná e Vargem Bonita, Santa Catarina. O canto de anúncio tem duração aproximada de $0,2 \mathrm{~s}$, sendo composto por notas simples pulsionadas com duração aproximada de $0,02 \mathrm{~s}$ emitidas em série (Figuras 14a-14c). Dentre os pulsos que compõem o canto de anúncio, o primeiro difere dos demais em $0,01 \mathrm{~s}(0,22-0,25 \mathrm{~s}$; $\mathrm{t}=-3,19 ; \mathrm{gl}=42 ; \mathrm{p}=0,001)$ e $1.136 \mathrm{~Hz}$ na frequência máxima $(2.866-4.000 \mathrm{~Hz} ; \mathrm{t}=-12,8 ; \mathrm{gl}=42 ; \mathrm{p}=0,00)$ (Tabela 7). Os cantos aqui descritos são muito similares ao apresentado por Kwet $(2001 \mathrm{a}, \mathrm{b})$ para populações de diversas localidades de Santa Catarina e todos os parâmetros estão contidos na variação registrada por esse autor.

Trachycephalus dibernardoi Kwet \& Solé (2008) - Figuras 1f-g.

Comentários taxonômicos. Exemplares de Trachycephalus dibernardoi, provenientes de São Francisco de Paula, (RS), foram preliminarmente identificados como Phrynohyas imitatrix (= Trachycephalus imitatrix, ver Faivovich et al. 2005), com base somente em morfologia (Kwet \& Di-Bernardo 1999). Posteriormente, com o aumento no número de exemplares coletados, provenientes de Machadinho, Rio Grande do Sul, e Seara, Santa Catarina, Kwet \& Solé (2008) encontram diferenças significativas entre os exempalres coletados e exemplares de T. imitatrix, descrevendo então Trachycephalus dibernardoi.

Comprimento rostro-cloacal. Foram medidos 22 machos e apenas uma fêmea (Anexo 1): os machos apresentaram $\mathrm{CRC}=63,96 \pm 2,52 \mathrm{~mm}(63,1-67,05 \mathrm{~mm})$. Essa variação de tamanho está contida na registrada por Kwet \& Solé (2008). A fêmea apresentou $\mathrm{CRC}=77,50 \mathrm{~mm}$.

Distribuição geográfica. Além dos exemplares da série tipo (Kwet \& Solé 2008), existem mais quatro registros considerados, até então, como de Trachycephalus imitatrix: São Bento do Sul, Santa Catarina, e Marumbi (Lutz 1973), Telêmaco Borba (Machado 2004) e Fazenda Rio Grande (Conte \& Rossa-Feres 2007), no Estado do Paraná. Lutz (1973) mencionou que os exemplares de T. imitatrix provenientes do sul do Brasil (Marumbi, Paraná, e São Bento do Sul, Santa Catarina apresentavam maior tamanho e padrão distinto de íris ("southern forms"), características que conferem com a descrição de T. dibernardoi. A análise do material proveniente de Telêmaco Borba evidenciou que os exemplares apresentam o mesmo padrão de manchas dorsais e maior tamanho, conferindo com a descrição de T. dibernardoi. A citação de $T$. dibernardoi para uma região próxima à Curitiba (Kwet \& Solé 2008), refere-se a um exemplar testemunho de um estudo realizado no município de Fazenda Rio Grande (DZSJRP 8810; Conte \& Rossa-Feres 2007).

Novos registros. Populações de T. dibernardoi foram registradas em mais três localidades: no PARNA das Araucárias, Santa Catarina, e por meio do registro de girinos (descrição em preparação; Conte, C.E. com. pess.) em São José dos Pinhais e Rio Negro, Paraná (Figura 15).

História natural. A espécie apresenta padrão reprodutivo explosivo (sensu Wells 1977), tendo sido registrado um evento de reprodução em agosto de 2007. Durante duas noites consecutivas, em uma aglomeração com mais de 230 indivíduos foram observados machos em atividade de vocalização e/ou se deslocando no interior da poça com movimentos aleatórios, provavelmente à procura de fêmeas. Os machos utilizavam toda a lâmina d'água e vocalizavam flutuando. Sua vocalização é de intensidade bastante alta, podendo ser ouvida a longas distâncias. Atualmente a espécie está na categoria "least concern" (preocupação menor) da (The International Union for Conservation of Nature 2009) e, no Rio Grande do Sul está classificada como espécie com "dados insuficientes" (Garcia \& Vinciprova 2003).

Análise do canto. Foi analisado o canto de três indivíduos provenientes de Telêmaco Borba, Paraná e PARNA das 


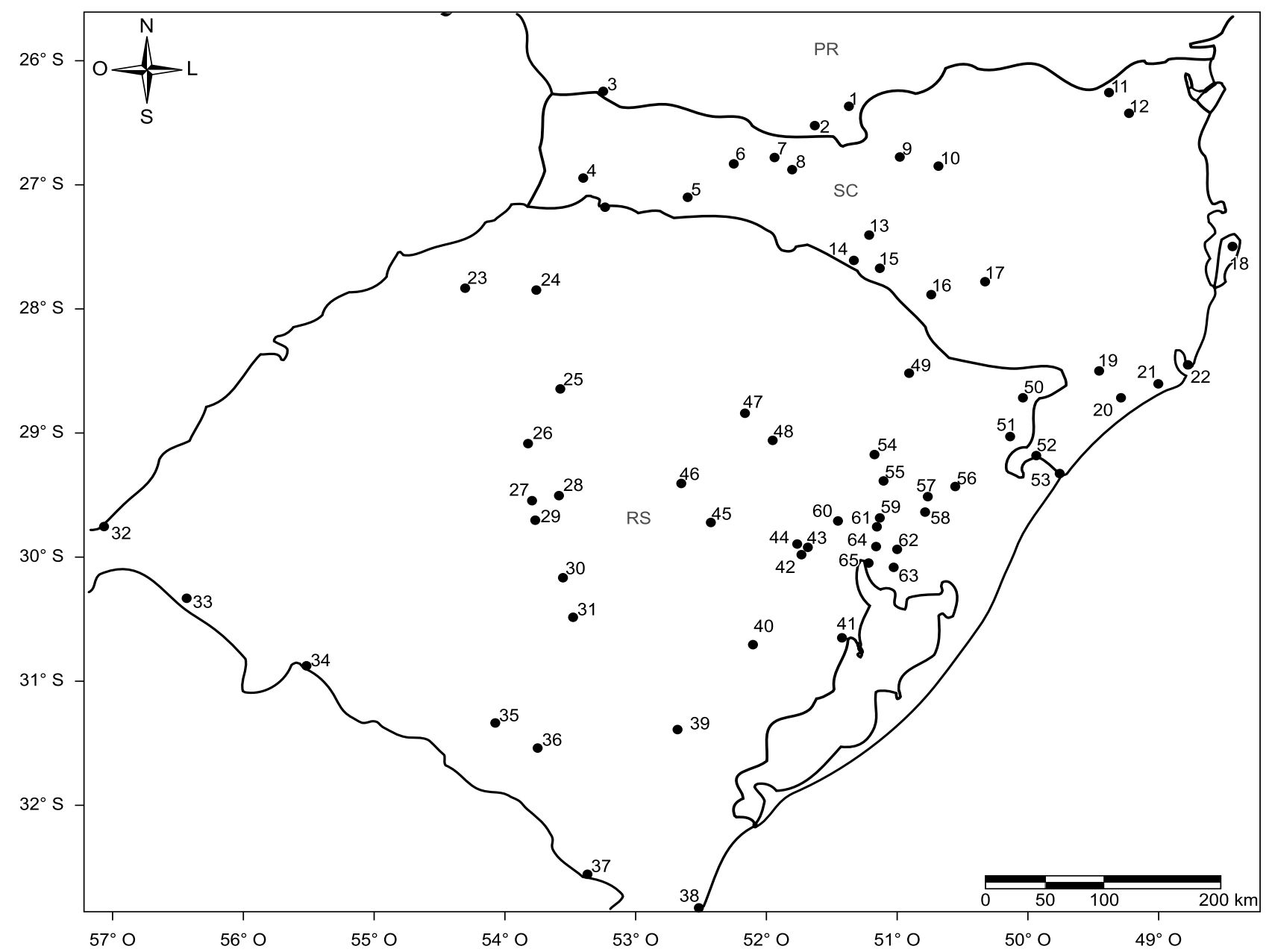

Figura 13. Mapa atualizado da distribuição geográfica de Scinax granulatus: 1. General Carneiro, 2. Palmas, 3. Marmeleiro, 4. São Domingos, 5. Chapecó, 6. Faxinal dos Guedes, 7. Ponte Serrada, 8. Vargem Bonita, 9. Caçador, 10. Lebon Régis, 11. São Bento do Sul, 12. Corupá, 13. Campos Novos, 14. Celso Ramos, 15. Anita Garibaldi, 16. Campo Belo do Sul, 17. Lages, 18. Florianópolis, 19. Treviso, 20. Içara, 21. Jaguaruna, 22. Laguna, 23. São Valentim, 24. Santo Antônio, 25. Cruz Alta, 26. Tupancirentã, 27. Itaara, 28. Ivorá, 29. Santa Maria, 30. São Sipé, 31. Caçapava, 32. Uruguaiana, 33. Quarai, 34. Santana do Livramento, 35. Bagé, 36. Candiota, 37. Jaguarão, 38. Estação Ecológica do Taim, 39. Canguçu, 40. Dom Feliciano, 41. Tapes, 42. São Jerônimo, 43. Triunfo, 44. General Câmara, 45. Santa Cruz do Sul, 46. Herveiras, 47. Arvorezinha, 48. Estrela, 49. Vacaria, 50. São José dos Ausentes, 51. Cambará, 52. Praia Grande, 53. Torres, 54. Caxias do Sul, 55. Nova Petrópolis, 56. São Francisco de Paula, 57. Três Coroas, 58. Taquara, 59. Novo Hamburgo, 60. Monte Negro, 61. São Leopoldo, 62. Gravataí, 63. Viamão, 64. Canoas e 65. Porto Alegre. Dados extraídos de: 1,2 e 8. Presente estudo; 3, 11, 13, 28, 30. Moresco et al. (2009); 6-11,17 e 19. Lucas (2008); 23-26, 28, 29,31,33-35, 37, 39, 41, 43, 45, 48, 49, 51-56, $58-63$ e 65. Braun, P.C. \& Braun, C.A.S. (1980); 27. Both et al. (2008); 38. Gayer et al. (1988); 5. Coleção CFBH e 9, 10, 13, 14, 16, 15, 18, 22, 32, 36, 40, 42, 44, 46, 47, 50, 57, 64. Coleção MCP.

Figure 13. Map of the current geographic distribution of Scinax granulatus: 1. General Carneiro, 2. Palmas, 3. Marmeleiro, 4. São Domingos, 5. Chapecó, 6. Faxinal dos Guedes, 7. Ponte Serrada, 8. Vargem Bonita, 9. Caçador, 10. Lebon Régis, 11. São Bento do Sul, 12. Corupá, 13. Campos Novos, 14. Celso Ramos, 15. Anita Garibaldi, 16. Campo Belo do Sul, 17. Lages, 18. Florianópolis, 19. Treviso, 20. Içara, 21. Jaguaruna, 22. Laguna, 23. São Valentim, 24. Santo Antônio, 25. Cruz Alta, 26. Tupancirentã, 27. Itaara, 28. Ivorá, 29. Santa Maria, 30. São Sipé, 31. Caçapava, 32. Uruguaiana, 33. Quarai, 34. Santana do Livramento, 35. Bagé, 36. Candiota, 37. Jaguarão, 38. Estação Ecológica do Taim, 39. Canguçu, 40. Dom Feliciano, 41. Tapes, 42. São Jerônimo, 43. Triunfo, 44. General Câmara, 45. Santa Cruz do Sul, 46. Herveiras, 47. Arvorezinha, 48. Estrela, 49. Vacaria, 50. São José dos Ausentes, 51. Cambará, 52. Praia Grande, 53. Torres, 54. Caxias do Sul, 55. Nova Petrópolis, 56. São Francisco de Paula, 57. Três Coroas, 58. Taquara, 59. Novo Hamburgo, 60. Monte Negro, 61. São Leopoldo, 62. Gravataí, 63. Viamão, 64. Canoas and 65. Porto Alegre. Data from: 1, 2 and 8. Present study; 3, 11, 13, 28, 30. Moresco et al. (2009); 6-11,17 and 19. Lucas (2008); 23-26, 28, 29,31,33-35, 37,39,41, 43,45,48,49,51-56, 58-63 and 65. Braun, P.C. \& Braun, C.A.S. (1980); 27. Both et al. (2008); 38. Gayer et al. (1988); 5. CFBH collection and 9, 10, 13, 14, 16, 15, 18, 22, 32, 36, 40, 42, 44, 46, 47, 50, 57 and 64. MCP collection.

Araucárias, Santa Catarina. O canto de anúncio consiste de uma longa série de notas pulsionadas emitidas em série, com duração aproximada de $0,9 \mathrm{~s}$. A amplitude das frequências está entre aproximadamente 210 e $2.000 \mathrm{~Hz}$, com frequência dominante em torno de $1.180 \mathrm{~Hz}$ (Figuras 16a-c, Tabela 8).

O canto de anúncio dos exemplares do Paraná apresenta nota mais longa $(0,817-1,213 \mathrm{~s})$ e taxa de repetição consideravelmente mais baixa (0,23-0,44 notas/s) que as registradas por Kwet \& Solé (2008), as quais têm duração variando entre $0,47-0,76 \mathrm{~s}$, intervalos entre notas variando entre $0,8-3,0 \mathrm{~s}$ e taxa de repetição entre 0,4-0,6 notas/s.
Esta variação, nas características temporais, pode ocorrer devido a diferenças na temperatura do ar no momento em que os cantos foram gravados $\left(13^{\circ} \mathrm{C}\right.$ no Paraná e $19,2{ }^{\circ} \mathrm{C}$ no Rio Grande do Sul). Já a frequência dominante é semelhante entre as populações dos diferentes estados, o que reforça a identidade da espécie.

Leptodactylus araucaria (Kwet \& Angulo 2002) - Figura 1h

Comentários taxonômicos. Descrita por Kwet \& Angulo (2002) sob o nome de Adenomera araucaria com base em exemplares coletados em São Francisco de Paula, Rio Grande do Sul. 

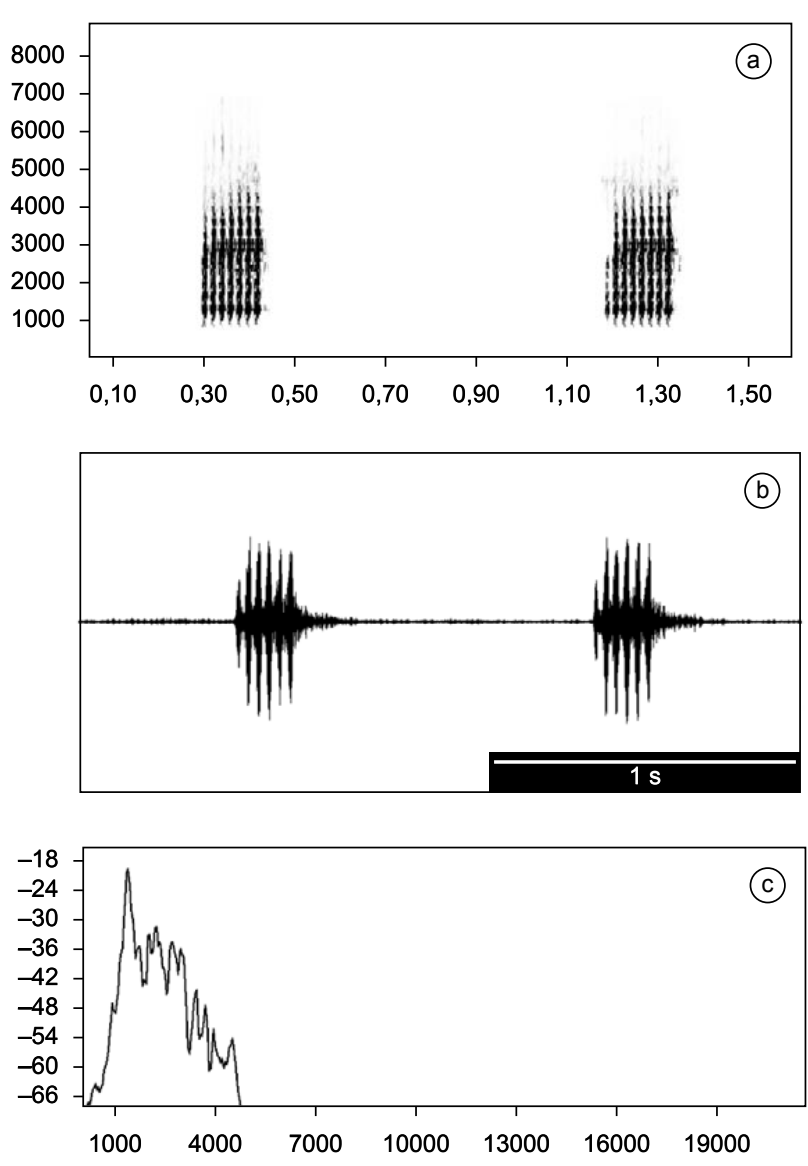

Figura 14. Canto de anúncio de Scinax granulatus. a) Sonograma e b) Oscilograma de dois cantos e c) espectro de potência de um canto. Vargem Bonita, Santa Catarina. Temperatura do ar: $16{ }^{\circ} \mathrm{C}$. Umidade relativa do ar: $80 \%$.

Figure 14. Advertisement call of Scinax granulatus. a) Sonogram and b) Oscilogram of two calls and c) Power spectrum of one call. Vargem Bonita, Santa Catarina State. Air temperature: $16{ }^{\circ} \mathrm{C}$. Relative air humidity: $80 \%$.
Distribuição geográfica. Além da localidade tipo a espécie é conhecida para outras sete localidades no Estado de Santa Catarina (Kwet 2007).

Novos registros. Os primeiros registros de L. araucaria no Estado do Paraná são para os municípios de General Carneiro e para a APA Serra da Esperança (Figura 17).

História natural. A região onde a espécie foi registrada no Paraná, abriga formações de Floresta com Araucária e pequenas manchas de campos (Castella \& Britez 2007). Machos de L. araucaria foram observados em atividade de vocalização nos meses de novembro e dezembro de 2008, tanto em áreas preservadas quanto alteradas, com densa cobertura de taquara ou com plantios de pinus, em locais com grande quantidade de serapilheira.

Análise do canto. Foram registrados os cantos de anúncio de quatro indivíduos provenientes de General Carneiro e da APA Serra da Esperança, Paraná. O canto de anúncio de L. araucaria é formado por uma única nota com aproximadamente 15 pulsos e duração média de $0,15 \mathrm{~s}$. Apresenta estrutura harmônica com modulação ascendente e frequência dominante entre 4.028 e $5.622 \mathrm{~Hz}$. A frequência fundamental também é modulada (Figuras 18a-18c, Tabela 9). A estrutura do canto registrada para exemplares do Paraná não difere da descrita por Kwet (2007).

Leptodactylus nanus Müller, 1922- Figura 1i.

Comentários taxonômicos. Descrita por Müller (1922) com base em indivíduos coletados em Corupá, Santa Catarina, e recentemente revalidada por Kwet (2007) como Adenomera nana, que até então estava sinonimizada com L. marmoratus (Heyer 1973). É provável que o nome L. marmoratus (Adenomera marmorata) esteja sendo aplicado a um complexo de espécies crípticas (CFB Haddad, com. pess.). No trabalho de redescrição, Kwet (2007) registrou L. nanus em nove localidades no Estado de Santa Catarina.

Comprimento rostro-cloacal. Foram medidos três machos (Anexo 1), que apresentaram $\mathrm{CRC}=18,30 \pm 0,79 \mathrm{~mm}$ (17,40-18,90 mm). Essa variação de tamanho está contida na registrada por Kwet (2007).

Tabela 7. Parâmetros bioacústicos do canto de anúncio de Scinax granulatus registrado em Vargem Bonita, Santa Catarina, General Carneiro e REVS dos Campos de Palmas, Paraná (Média \pm desvio padrão (amplitude); número de notas analisadas/número de indivíduos), e por Kwet (2001a, b) em diversas localidades de Santa Catarina (amplitude).

Table 7. Bioacoustic parameters of the advertisement call of Scinax granulatus, recorded in Vargem Bonita, Santa Catarina State, General Carneiro and Refúgio da Vida Silvestre dos Campos de Palmas, Paraná State (Mean \pm standard deviation (range); number of notes analyzed /number of individuals), and by at several localities in Santa Catarina State (range).

\begin{tabular}{lcc}
\hline \multicolumn{1}{c}{ Parâmetros } & Canto de anúncio \\
\cline { 2 - 3 } & (Presente estudo) & (Kwet 2001a, b) \\
\hline Duração do canto & $0,24 \pm 0,04(0,21-0,29) ; 43 / 4$ & $0,08-0,26$ \\
Frequência mínima & $876 \pm 138(819,8-948,3) ; 43 / 4$ & 800 \\
Frequência máxima da primeira nota & $2.866 \pm 399(2.050-3.871), 22 / 3$ & - \\
Frequência máxima das demais notas & $4.012,3 \pm 636,3(3.905-4.401) ; 43 / 4$ & 4.200 \\
Frequência dominante & $1.277 \pm 73(1.124,6-1.571,7) ; 43 / 4$ & $980-1.480$ \\
Duração do primeiro pulso & $0,02 \pm 0,001(0,018-0,026) ; 22 / 3$ & - \\
Duração dos demais pulsos & $0,02 \pm 0,001(0,021-0,029) ; 82 / 4$ & $0,08-0,26$ \\
Número de pulsos por nota & $9,2 \pm 1,6(7-11) ; 43 / 4$ & $5-10$ \\
Taxa de repetição (canto/s) & $0,61 \pm 0,15(0,6-1,1) ; 43 / 4$ & - \\
Intervalo entre as notas & $1,26 \pm 0,3(0,8-2) ; 43 / 4$ & $0,3-2$ \\
Pulsos/s & $47,3 \pm 4,2(39-54) ; 43 / 4$ & $40-50$
\end{tabular}




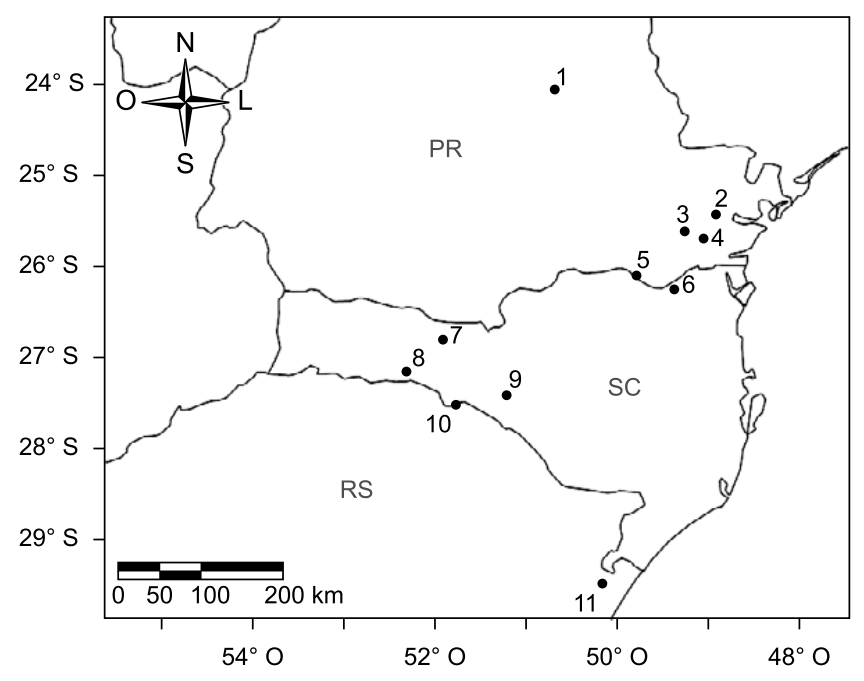

Figura 15. Mapa atualizado da distribuição geográfica de Trachycephalus dibernardoi. 1. Telêmaco Borba, 2. Marumbi, 3. Fazenda Rio Grande, 4. São José dos Pinhais, 5. PARMU São Luis de Tolosa, 6. São Bento do Sul, 7. PARNA das Araucárias, 8. Seara, 9. Campos Novos, 10. Machadinho e 11. São Francisco de Paula. Dados extraídos de: 1,3-5 e 7. Presente estudo; 2 e 6. Lutz (1973); 8,9 e 11. Kwet \& Sole (2008) e 9. Coleção MCP.

Figure 15. Map of the current geographic distribution of Trachycephalus dibernardoi. 1. Telêmaco Borba, 2. Marumbi, 3. Fazenda Rio Grande, 4. São José dos Pinhais, 5. Parque Municipal São Luis de Tolosa, 6. São Bento do Sul, 7. Parque Nacional das Araucárias, 8. Seara, 9. Campos Novos, 10. Machadinho e 11. São Francisco de Paula. Data from: 1,3-5 and 7. Present study; 2 and 6. Lutz (1973); 8,9 and 11. Kwet \& Sole (2008) and 9. MCP colection.

Distribuição geográfica. Até o momento, as duas populações no Estado do Paraná, consideradas pelos autores como L. marmoratus, nos municípios de Tijucas do Sul (Conte \& Machado 2005) e em São José dos Pinhais (Conte \& Rossa-Feres 2006), através das análises do canto de anúncio, são reconhecidas como L. nanus.

Novos registros. Leptodactylus nanus também foi registrada no PARMU de São Luiz de Tolosa, Estado do Paraná (Figura 19).

História natural. Machos em atividade de vocalização foram registrados entre outubro e fevereiro, sobre a serapilheira ou empoleirados sobre a vegetação rasteira, com pico de atividade durante o crepúsculo vespertino. Foram observados vocalizando tanto no interior quanto na borda de fragmentos florestais.

Análise do canto. O canto de anúncio de Leptodactylus nanus é formado por uma única nota com duração média de $0,10 \mathrm{~s}$. Apresenta estrutura harmônica com frequência fundamental entre $2.146 \mathrm{~Hz}$ e $2.450 \mathrm{~Hz}$ e frequência dominante de aproximadamente $4.646 \mathrm{~Hz}$ (Figuras 20a-20c, Tabela 10). O canto proveniente de exemplares do Estado do Paraná é muito similar ao encontrado por Kwet (2000) Kwet et al. (2009) em diversas localidades de Santa Catarina e todos os parâmetros acústicos estão contidos na variação registrada por esse autor.

\section{Considerações Finais}

Muitas espécies têm sido revalidadas nos últimos anos com base em análises morfológicas e/ou bioacústicas (Haddad \& Pombal 1998, Kwet \& Solé 2005, Kwet 2007, Izecksohn \& Carvalho-e-Silva 2008). A análise da vocalização dos anuros tem possibilitado a identificação de espécies pertencentes a grupos complexos, bem como a descrição
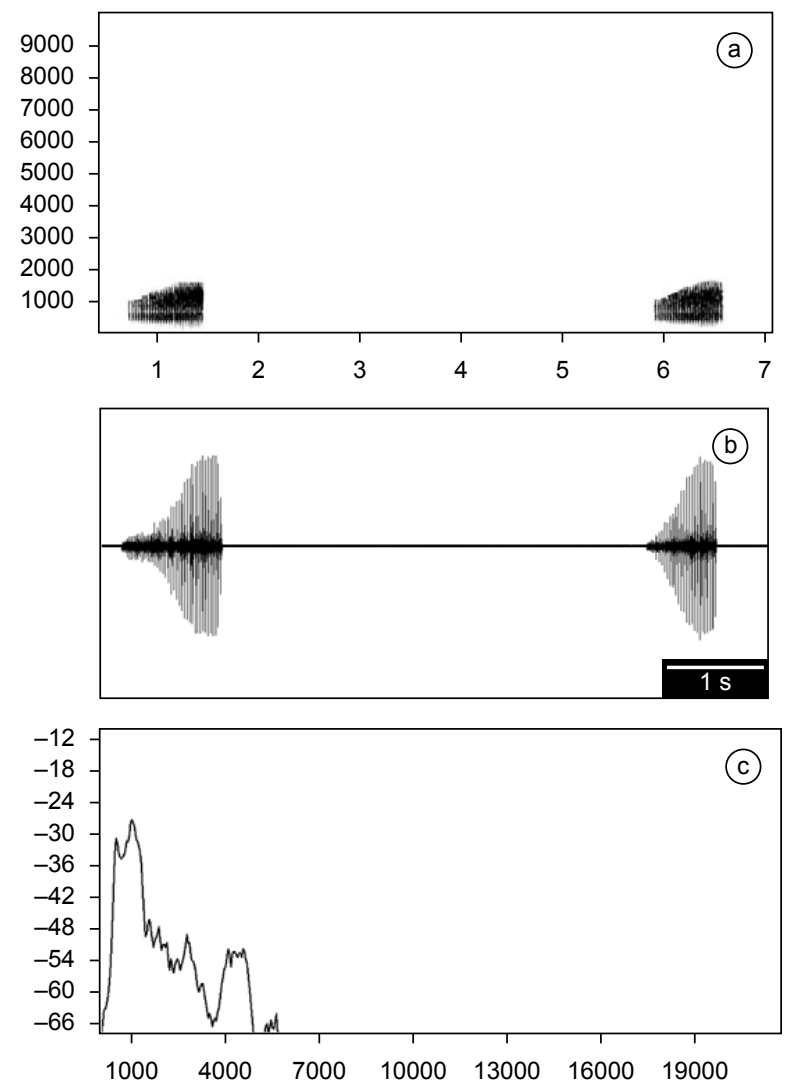

Figura 16. Canto de anúncio de Trachycephalus dibernardoi. a) Sonograma, b) Oscilograma e c) espectro de potência. Telêmaco Borba, Paraná. Temperatura do ar: $13{ }^{\circ} \mathrm{C}$. Umidade relativa do ar: $90 \%$.

Figure 16. Advertisement call of Trachycephalus dibernardoi. a) Sonogram, b) Oscilogram and c) Power spectrum. Telêmaco Borba, Paraná state. Air temperature: $13{ }^{\circ} \mathrm{C}$. Relative air humidity: $90 \%$.

e diferenciação de espécies crípticas como, por exemplo, as dos complexos de Leptodactylus marmoratus (ver revisão em Kwet et al. 2009), de Scinax perspusillus (ver revisão em Silva \& Alves-Silva 2008) e de Physalaemus signifer (ver comentários em Pimenta et al. 2005, Weber et al. 2005). Ainda, nos últimos anos, tem-se detectado com base em análises moleculares que espécies consideradas cosmopolitas são, na verdade, espécies crípticas (Wynn \& Heyer 2001, Heyer \& Reid 2003, Camargo et al. 2006). Considerando que muitos grupos de anfíbios carecem de revisão taxonômica (Faivovich et al. 2005), descrições minuciosas da vocalização são importantes, pois a análise bioacústica é uma importante ferramenta para identificação de espécies (Cocroft \& Ryan 1995, Haddad \& Pombal 1998).

A falta de reconhecimento de muitos táxons contidas em complexos de espécies, além de subestimar a diversidade de anuros no Brasil, resulta numa interpretação errônea sobre os padrões ecológicos e distribuição geográfica. Por exemplo, não há concordância entre a distribuição das espécies apresentadas neste estudo com os mapas elaborados pela The International Union for Conservation of Nature 2009: algumas distribuições são disjuntas (Ischnocnema henselii), superestimadas (Scinax granulatus e Leptodactylus marmoratus) ou subestimadas (Dendropsophus anceps, D. nahdereri, Pseudis cardosoi e L. araucaria). Tal efeito é ainda mais preocupante, considerando-se que a distribuição geográfica é um dos principais critérios utilizados para a definição do status de ameaça de uma espécie. Por exemplo, no Paraná, 
O impacto da vocalização no reconhecimento de espécies de anuros

Tabela 8. Parâmetros bioacústicos do canto de anúncio de Trachycephalus dibernardoi registrado no PARNA das Araucárias, Santa Catarina e Telêmaco Borba, Paraná, e por Kwet \& Solé (2008) em São Francisco de Paula, Rio Grande do Sul. Média \pm desvio padrão (amplitude); número de notas analisadas/ número de indivíduos.

Table 8. Bioacoustic parameters of the advertisement call of Trachycephalus dibernardoi, recorded in Parque Nacional das Araucárias, Santa Catarina State, and Telêmaco Borba, Paraná State, and by Kwet \& Solé (2008) at São Francisco de Paula, Rio Grande do Sul State. Mean \pm standard deviation (range); number of notes analyzed /number of inivividuals.

\begin{tabular}{lcc}
\hline \multicolumn{1}{c}{ Parâmetros } & Canto de anúncio & (Kresente estudo) \\
\cline { 2 - 3 } & $0,93 \pm 0,12(0,817-1,213) ; 20 / 3$ & $0,604(0,47-0,76) ; 25 / 1$ \\
Duração do canto & $212 \pm 30,67(209,5-344) ; 20 / 3$ & - \\
Frequência mínima $(\mathrm{Hz})$ & $2.016,1 \pm 140,7(1.746-2.221) ; 20 / 3$ & - \\
Frequência máxima $(\mathrm{Hz})$ & $1.181,1 \pm 194,52(1.016,7-1.979) ; 20 / 3$ & $1.550(1.100-1.800) ; 25 / 1$ \\
Frequência dominante $(\mathrm{Hz})$ & $33,95 \pm 4,01(28-42) ; 20 / 3$ & $37,6(31-49) ; 25 / 1$ \\
Número de notas por canto & $0,33 \pm 0,7(0,23-0,44) ; 20 / 3$ & $0,4-0,6 ; 25 / 1$ \\
Taxa de repetição (notas/s) &
\end{tabular}

Tabela 9. Parâmetros bioacústicos do canto de anúncio de Leptodactylus araucaria registrado na APA Serra da Esperança e General Carneiro, Paraná [Média \pm desvio padrão (amplitude); número de notas analisadas/número de indivíduos], e por Kwet (2007) em diversas localidades de Santa Catarina e Rio Grande do Sul (valor mínimo e máximo registrado; número de cantos analisados/ número de indivíduos).

Table 9. Bioacoustic parameters of the advertisement call of Leptodactylus araucaria, recorded in APA Serra da Esperança and General Carneiro, Paraná State [Mean \pm standard deviation (range); number of notes analyzed /number of individuals], and by Kwet (2007) at several localities in Santa Catarina and Rio Grande do Sul states (value minimum and maximum recorded; number of notes analysed/ number of individuals).

\begin{tabular}{lcc}
\hline \multicolumn{1}{c}{ Parâmetros } & Canto de anúncio & (Kwesente estudo) \\
\cline { 2 - 3 } & $0,157 \pm 0,03(0,107-0,268) ; 65 / 4$ & $75,7-189,9 ; 120 / 12$ \\
Duração do canto & $15,2 \pm 3,4(10-21) ; 65 / 4$ & $6-18 ; 120 / 12$ \\
Número de pulsos & $2.151,2 \pm 83,23(1.973-2.334) ; 65 / 4$ & $2.200-2.500 ; 120 / 12$ \\
Frequência fundamental - início do canto & $2.819 \pm 99(2.634-3.041) ; 65 / 4$ & $2.640-2.980 ; 120 / 4$ \\
Frequência fundamental - final do canto & $5.070,6 \pm 192,3(4.630,9-5.321) ; 65 / 4$ & $4.620-5.650 ; 120 / 12$ \\
Frequência dominante & $4.028,5 \pm 143,7(3.677-4.438) ; 65 / 4$ & $6.990-7.960 ; 120 / 12$ \\
Frequência máxima atingida & $5.622,4 \pm 257,6(5.216-6.206) ; 65 / 4$ & - \\
Frequência mínima atingida (fora harmônico) & $0,93 \pm 0,2(0,45-1,49) ; 19 / 4$ & $0,43-1,2 ; 120 / 12$ \\
Taxa de repetição & $1,22 \pm 0,53(0,715-2,982) ; 65 / 4$ & - \\
Intervalo entre notas & & \\
\hline
\end{tabular}

D. anceps é considerada como criticamente ameaçada por ter uma distribuição restrita e por ser associada com áreas antropizadas (Mikich \& Bérnils 2004). Entretanto, o encontro de três populações nesse estado (Ribeirão Claro - Conte et al. 2009; Ibaiti e Figueira presente estudo), indica que $D$. anceps tem uma distribuição mais ampla e que pode utilizar áreas modificadas por ação humana para reprodução. Assim, os registros aqui apresentados fundamentam a revisão do grau de ameaça sobre esta espécie numa próxima revisão da lista estadual de animais ameaçados. Por outro lado, o registro de Pseudis cardosoi é o primeiro para o território paranaense e, embora a população tenha sido registrada em uma unidade de conservação, pode estar ameaçada pelo uso inadequado do solo e alteração de habitat (Weirich Neto \& Rocha 2007, Overbeck et al. 2007), o que permite considerar sua inclusão na lista estadual de espécies ameaçadas.

Nos últimos anos, diversos estudos resultaram no registro de espécies antes desconhecidas para os Estados do Paraná (Bernarde 1998 \& 1999, Lingnau 2000, Lingnau \& Bastos 2002, Machado \& Conte 2001, Machado \& Haddad 2001, Conte et al. 2005, Lima et al. 2005, Conte et al. 2009, Moresco et al. 2009) e para Santa Catarina (Braun 1978, Garcia \& Vinciprova 1998, Giasson et al. 2001, Kwet 2004, Langone 1997, Lingnau \& Di-Bernardo 2006). Esses resultados, juntamente com descrições de novos táxons (Castanho \& Haddad 2000, Caramaschi \& Cruz 2002, Baldissera et al. 2004, Ribeiro et al. 2005, Alves et al. 2006, Caramaschi \& Pombal 2006, Cruz et al. 2008, Garcia et al. 2008, Langone et al. 2008, Lingnau et al. 2008, Steinbach-Padilha 2008) ampliaram a riqueza de anfíbios no Paraná de 120 (Mikich \& Bérnils 2004) para 142 espécies. Já Santa Catarina destaca-se pela grande quantidade

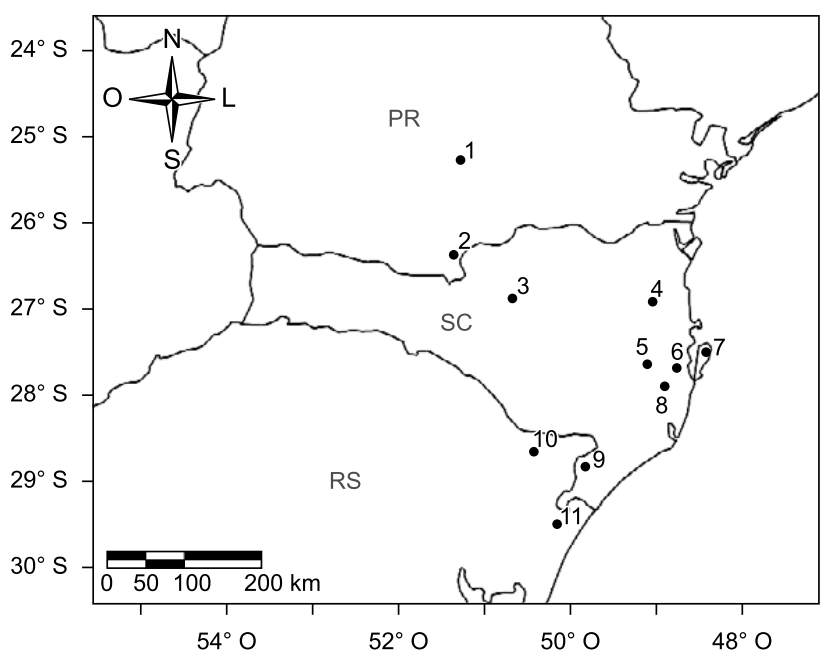

Figura 17. Mapa atualizado da distribuição geográfica de Leptodactylus araucaria. 1. APA Serra da Esperança, 2. General Carneiro, 3. Lebon Régis, 4. Blumenau, 5. Taquaras, 6. Santo Amaro da Imperatriz, 7. Florianópolis, 8. São Bonifácio, 9. Timbé do Sul, 10. Bom Jesus e 11. São Francisco de Paula (localidade tipo). Dados extraídos de: 1 e 2. Presente estudo; 3-9. Kwet (2007) e 7,11 e 12. Kwet \& Angulo (2002).

Figure 17. Map of the current geographic distribution of Leptodactylus araucaria. 1. Área de proteção Ambiental Serra da Esperança, 2. General Carneiro, 3. Lebon Régis, 4. Blumenau, 5. Taquaras, 6. Santo Amaro da Imperatriz, 7. Florianópolis, 8. São Bonifácio, 9. Timbé do Sul, 10. Bom Jesus and 11. São Francisco de Paula (localit type). Data from: 1 and 2. Present study; 3-9. Kwet (2007) and 7,11 and 12. Kwet \& Angulo (2002). 
Tabela 10. Parâmetros bioacústicos do canto de anúncio de Leptodactylus nanus, registrado em São José dos Pinhais e PARMU São Luis de Tolosa, Paraná [Média \pm desvio padrão (amplitude); notas analisadas/número de indivíduos], e por Kwet (2007) em diversas localidades de Santa Catarina (valor mínimo e máximo registrado; número de cantos analisados/ número de indivíduos).

Table 10. Bioacoustic parameters of the advertisement call of Leptodactylus nanus, recorded in São José dos Pinhais and Parque Municipal São Luis de Tolosa, Paraná State [Mean \pm standard deviation (range); number of notes analyzed /number of individuals], and by Kwet (2007) at several localities in Santa Catarina State (value minimum and maximum recorded; number of notes analysed/ number of individuals).

\section{Parâmetros}

Canto de anúncio

\begin{tabular}{lcc} 
& (Presente estudo) & (Kwet 2007) \\
\cline { 2 - 3 } & $0,102 \pm 0,02(0,069-0,157) ; 52 / 3$ & $75,9-110,7 ; 108 / 11$ \\
Duração do canto & $1 ; 52 / 3$ & $1 ; 108 / 11$ \\
Número de pulsos & $2.146,2 \pm 65,99(2.033-2.351) ; 52 / 3$ & $2.300-2.600 ; 108 / 11$ \\
Frequência fundamental - mínimo & $2.450,1 \pm 59,2(2.334-2.599) ; 52 / 3$ & $2.600-2.800 ; 108 / 11$ \\
Frequência fundamental - máximo & $4.646 \pm 120,3(4.516,6-4.897) ; 52 / 3$ & $4.800-5.440 ; 108 / 11$ \\
Frequência dominante & $6.983 \pm 157,9(6.648-7.249) ; 52 / 3$ & $6.900-7.800 ; 108 / 11$ \\
Frequência máxima atingida & $2.683,4 \pm 158,2(2.510-3.129) ; 52 / 3$ & - \\
Frequência mínima atingida (fora harmônico) & $0,58 \pm 0,3(1,172-5,347) ; 28 / 3$ & $0,3-0,61 ; 108 / 11$ \\
Taxa de repetição & $2,48 \pm 1,3(1,72-5,34) ; 52 / 3$ & - \\
Intervalo entre notas & & \\
\hline
\end{tabular}
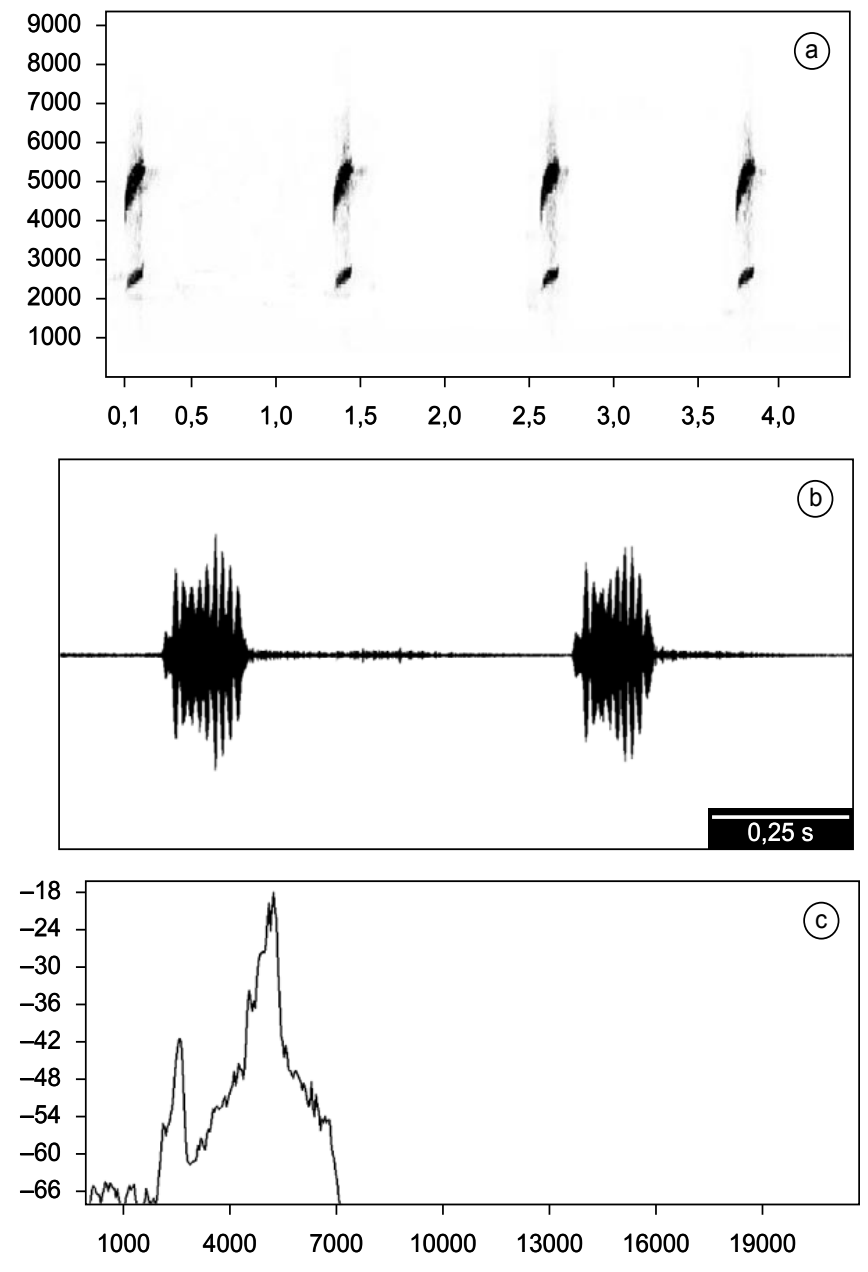

Figura 18. Canto de anúncio de Leptodactylus araucaria. a) Sonograma, b) Oscilograma e c) espectro de potência. General Carneiro, Paraná. Temperatura do ar: $23{ }^{\circ} \mathrm{C}$. Umidade relativa do ar: $80 \%$.

Figure 18. Advertisement call of Leptodactylus araucaria. a) Sonogram, b) Oscilogram and c) Power spectrum. General Carneiro, Paraná State. Air temperature: $23{ }^{\circ} \mathrm{C}$. Relative air humidity: $80 \%$.

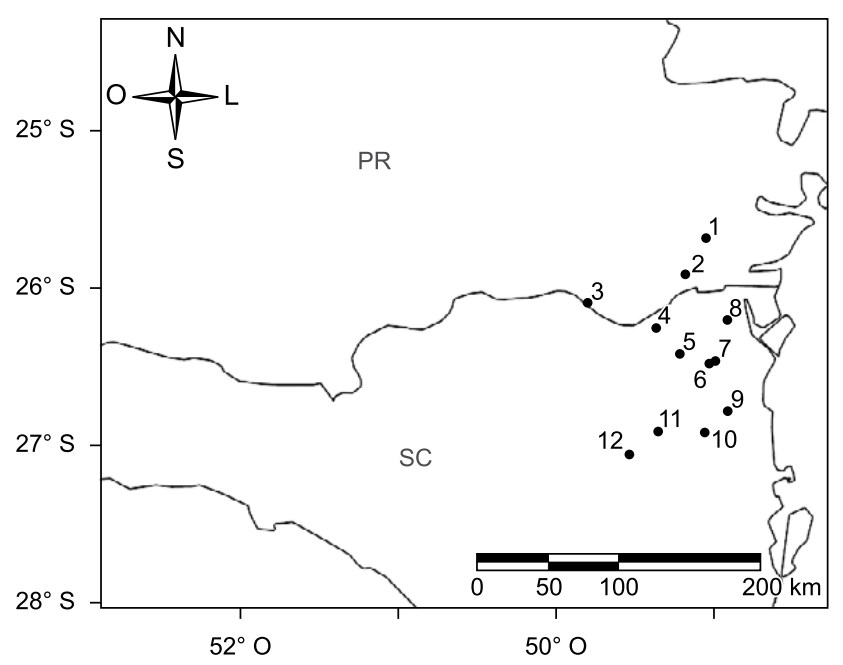

Figura 19. Mapa atualizado da distribuição geográfica de Leptodactylus nanus. 1. São José dos Pinhais, 2. Tijucas do Sul, 3. PARMU São Luis de Tolosa, 4. São Bento do Sul, 5. Corupá, 6. Jaraguá do Sul, 7. Guaramirim, 8. Pirabeiraba, 9. Morro do Baú, 10. Blumenau, 11. Rodeio e 12. Ibirama. Dados extraídos de: 1-3. Presente estudo e 4-12. Kwet (2007).

Figure 19. Map of the current geographic distribution of Leptodactylus nanus. 1. São José dos Pinhais, 2. Tijucas do Sul, 3. Parque Municipal São Luis de Tolosa, 4. São Bento do Sul, 5. Corupá, 6. Jaraguá do Sul, 7. Guaramirim, 8. Pirabeiraba, 9. Morro do Baú, 10. Blumenau, 11. Rodeio and 12. Ibirama. Data from: 1-3. Present study and 4-12. Kwet (2007).

de espécies descritas a partir de material tipo coletado $(n=33$, Frost 2009). Atualmente são conhecidas 110 espécies, número muito superior à lista apresentada por Müller (1922) (n=38, Lucas 2008). Apesar do Brasil deter a maior riqueza de anfíbios do mundo, com 877 espécies (Sociedade Brasileira de Herpetologia 2010), a real diversidade está muito aquém de um conhecimento minimamente satisfatório e o número de espécies reconhecidas para esses dois estados deve aumentar com o incremento no número de estudos e com o uso de novas abordagens, como análises bioacústicas e moleculares (Kwet \& Solé 2005, Kwet 2007, Kwet et al. 2009). 

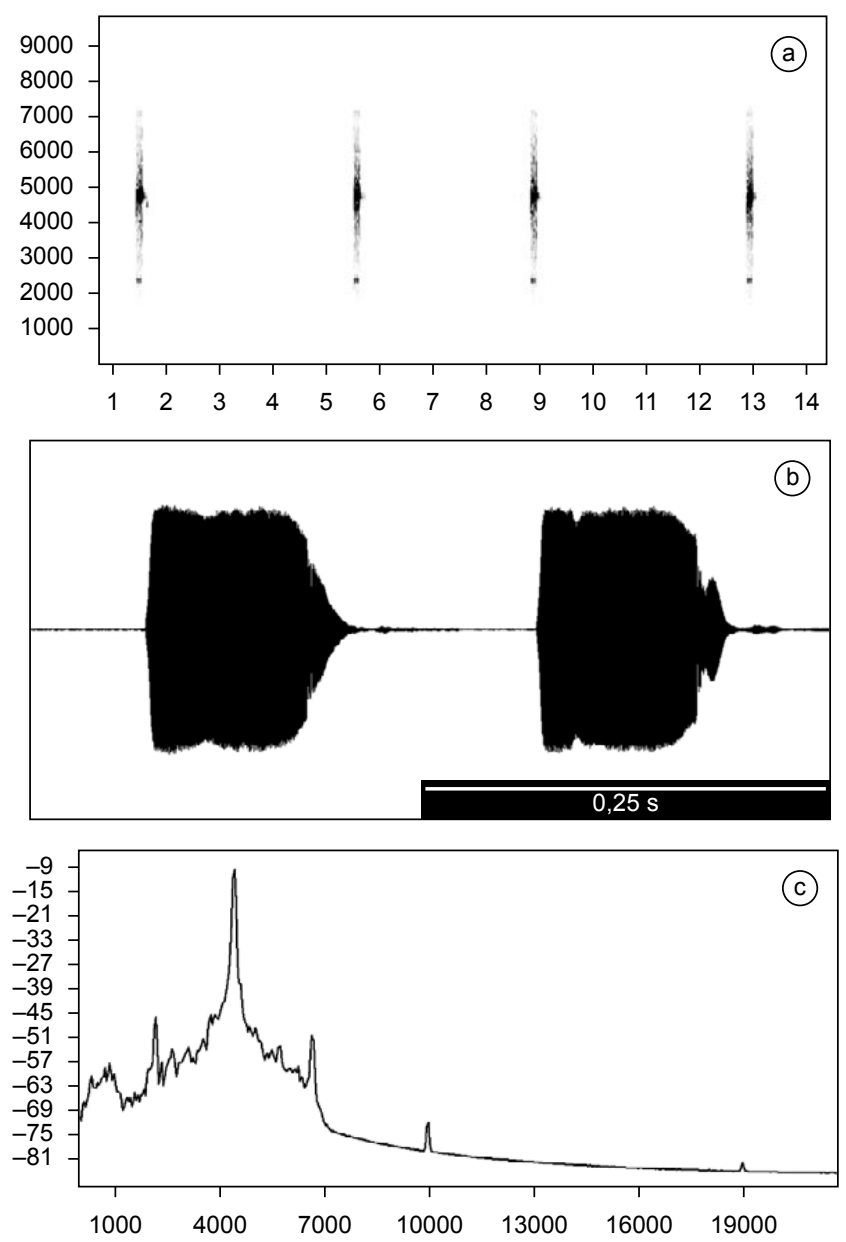

Figura 20. Canto de anúncio de Leptodactylus nanus. a) Sonograma, b) Oscilograma e c) espectro de potência (C). São José dos Pinhais, Paraná. Temperatura do ar: $23{ }^{\circ} \mathrm{C}$. Umidade relativa do ar: $80 \%$.

Figure 20. Advertisement call of Leptodactylus nanus. a) Sonogram, b) Oscilogram and c) Power spectrum. São José dos Pinhais, Paraná State. Air temperature: $18{ }^{\circ} \mathrm{C}$. Relative air humidity: $80 \%$.

\section{Agradecimentos}

A Janael Ricetti, Darlene da Silva Gonçalves e Eduardo José dos Santos pelo auxílio nas fases de campo em Palmas e Rio Negro. A Gledson Vigiano Bianconi, Janael Ricetti e Alberto Urben Filho pelas críticas e contribuições na versão preliminar. A Hori Consultoria Ambiental, a Companhia Paranaense de Energia (COPEL) e Instituto de Tecnologia para o Desenvolvimento (LACTEC) pelo suporte logístico no município de Figueira. A Celulose Irani pelo suporte logístico em Vargem Bonita. A Indústrias Pedro Pizzatto pelo suporte logístico em General Carneiro. A Indústria de Madeiras Tozzo Ltda pelo suporte logístico no Parque Nacional das Araucárias. Ao Senhor Joaquim Osório Ribas pelo apoio logístico no Refúgio da Vida Silvestre dos Campos de Palmas. A prefeitura de Rio Negro pela autorização do desenvolvimento do projeto "Riqueza e distribuição temporal da anurofauna em uma localidade do sudeste do Estado do Paraná, Brasil", no Parque Municipal São Luis de Tolosa. Ao Instituto Chico Mendes de Conservação e Biodiversidade pela autorização de coleta em Unidades de Conservação (Licença nº 13282-5). À Coordenadoria de Aperfeiçoamento de Pessoal de Nível Superior CAPES pela bolsa concedida a C.E.C.

\section{Referências Bibliográficas}

ALVES, A.C.R., RIBEIRO, L.F., HADDAD, C.F.B. \& REIS, S.F. 2006. Two new species of Brachycephalus (Anura: Brachycephalidae) from the Atlantic forest in Paraná state, Southern Brazil. Herpetologica 62(2):221-233.

ARGÔLO, A.J.S. 2000. Geographic distribution: Hyla anceps. Herpetol. Rev. 31(2):109.

BALDISSERA, Jr., F.A., CARAMASCHI, U. \& HADDAD, C.F.B. 2004. Review of the Bufo crucifer species group, with descriptions of two new related species (Amphibia, Anura, Bufonidae). Arq. Mus. Nac. Rio J. 62(3):255-282.

BASTAZINI, C.V., MUNDURUCA, J.F.V., ROCHA, P.L.B \& NAPOLI, M.F. 2007. Amphibians from the Restinga of Mata de São João, Bahia, Brazil: which environmental variables are associated with the anuran composition? Herpetologica 63(4):459-471.

BAUER, A.M.R., GÜNTHER, R. \& KLIPFEL, M. 1995. The Herpetological Contributions of Wilhelm C. H. Peters (1815-1883). Thomson-Shore, Ithaca.

BEE, M.A. \& BOWLING, A.C. 2002. Socially Mediated Pitch Alteration by Territorial Male Bullfrogs, Rana catesbeiana. J. Herpetol. 36(1):140-143.

BEE, M.A., PERRIL, S.A. \& OWEN, P. 1999. Size assessment in simulated territorial encounters between male green frogs (Rana clamitans). Behav. Ecol. Sociobiol. 45:177-184.

BEE, M.A., PERRILL S.A. \& OWEN P.C. 2000. Male green frogs lower the pitch of acoustical signal in defense of territories: a possible dishonest signal of size? Behav. Ecol. 11(2):169-177.

BERNARDE, P.S. 1998. Geographic distribution: Hyla punctata (NCN). Herpetol. Rev. 29(4):246.

BERNARDE, P.S. 1999. Geographic distribution: Hyla uruguaya. Herpetol. Rev. 30(4):230.

BOKERMANN, W.C.A. 1967. Notas sobre cantos nupciais de anfíbios brasileiros I. (Anura). An. Acad. Bras. Cienc. 39(3-4):441-443.

BOTH, C., KAEFER, I.L., SANTOS, T.G. \& CECHIN, S.T.Z. 2008. An austral anuran assemblage in the Neotropics: seasonal occurrence correlated with photoperiod. J. Nat. Hist. 42(3-4):205-222.

BRANDÃO, R.A., GARDA, A., BRAZ, V. \& FONSECA, B. 2003. Observations on the ecology of Pseudis bolbodactyla (Anura, Pseudidae) in central Brazil. Phyllomedusa 2(1):3-8.

BRAUN, P.C. \& BRAUN, C.A.S. 1980. Lista prévia dos anfíbios do Estado do Rio Grande do Sul, Brasil. Iheringia Ser. Zool. 56:121-146.

BRAUN, P.C. 1978. Ocorrência de Melanophryniscus stelzneri dorsalis (Mertens, 1933) no estado de Santa Catarina, Brasil (Anura, Bufonidae). Iheringia Ser. Zool. 51:39-41.

CAMARGO, A., SÁ, R.O. \& HEYER, W.R. 2006. Phylogenetic analyses of mtDNA sequences reveal three cryptic lineages in the widespread Neotropical frog Leptodactylus fuscus (Schneider, 1799) (Anura, Leptodactylidae). Biol. J. Linn. Soc. 87:325-341.

CANDOLIN, U. 2003. The use of multiple cues in mate choice. Biol. Rev. 78(4):575-595.

CANELAS, A.S. \& BERTOLUCI, J. 2007. Anurans of the Serra do Caraça, southeastern Brazil: species composition and phenological patterns of calling activity. Iheringia Ser. Zool. 97(1):21-16.

CARAMASCHI, U. \& CRUZ, C.A.G. 2002. Taxonomic status of Atelopus pachrhrynus Miranda-Ribeiro, 1920, redescription of Melanophryniscus tumifrons (Boulenger, 1905), and descriptions of two new species of Melanophryniscus from the state of Santa Catarina, Brazil (Amphibia, Anura, Bufonidae). Arq. Mus. Nac. Rio J. 60(4):303-314.

CARAMASCHI, U. \& POMBAL, Jr., J.P. 2006. A new species of Rhinella Fitzinger, 1826 from the Atlantic rain forest, eastern Brazil (Amphibia, Anura, Bufonidae). Pap. Avulsos Zool. 46(23):251-259.

CARVALHO-E-SILVA, A.M.P.T., SILVA, G.R. \& CARVALHO-E-SILVA, S.P. 2008. Anuros da Reserva Rio das Pedras, Mangaratiba, RJ, Brasil. 
Biota Neotrop. 8(1): http://www.biotaneotropica.org.br/v8n1/en/abstract ?inventory+bn02608012008 (último acesso em 05/02/2010).

CASTANHO, L. \& HADDAD, C.F.B. 2000. New species of Eleutherodactylus (Amphibia: Leptodactylidae) from Guaraqueçaba, Atlantic Forest of Brazil. Copeia 33(3):777-781.

CASTELLA, P.R. \& BRITEZ, R.M. 2004. A floresta com araucária no Paraná: conservação e diagnóstico dos remanescentes florestais. Ministério do Meio Ambiente, Brasília, DF.

CHANNING, A., MOYER, D. \& BURGER, M. 2002. Cryptic species of sharp-nosed reed frogs in the Hyperolius nasutus complex: advertisement calls differences. Afr. Zool. 37:91-99.

CLARKE, K.R. \& WARWICK, R.M. 1994. Chance in marine communities: an approach to statistical analysis and interpretation. Bournemouth, Bourne Press.

CLARKE, K.R. 1993. Non-parametric multivariate analysis of changes in community structure. Aust. J. Ecol. 18:117-143.

COCHRAN, D.M. 1955. Frogs of south-Eastern Brazil. Bull. U. S. Natl. Mus. 201:1-423.

COCROFT, R.B. \& RYAN, M.J. 1995. Patterns of advertisement call evolution in toads and chorus frogs. Anim. Behav. 49(2):283-303.

CONTE, C.E. \& MACHADO, R.A. 2005. Riqueza de espécies e distribuição espacial e temporal em comunidade de anfíbios anuros (Amphibia, Anura) em uma localidade do Município de Tijucas do Sul, Paraná, Brasil. Rev. Bras. Zoo. 22(4):940-948.

CONTE, C.E. \& ROSSA-FERES, D. de C. 2007. Riqueza e distribuição espaço-temporal de anuros em um remanescente de Floresta com Araucária no sudeste do Paraná. Rev. Bras. Zoo. 24:1025-1037.

CONTE, C.E., GAREY, M.V., LINGNAU, R., SILVA, M.X., ARMSTRONG, CG. \& HARTMANN, M.T. 2009. Amphibia, Anura, Limnomedusa macroglossa, Dendropsophus anceps, D. berthalutzae, D. seniculus, Scinax littoralis: new state records, distribution extension and filling gaps. Check List 5:154-172.

CONTE, C.E., LINGNAU, R. \& KWET, A. 2005. Description of the advertisement call of Hyla ehrhardti Müller, 1924 and new distribution records (Anura: Hylidae). Salamandra 41(3):147-151.

CONTE, E.C. \& ROSSA-FERES, D. de C. 2006. Diversidade e ocorrência temporal da anurofauna (Amphibia, Anura) em São José dos Pinhais, Brasil. Rev. Bras. Zoo. 23(1):162-175.

CRUZ, C.A.G., FEIO, R.N. \& NASCIMENTO, L.B. 2008. A new species of Phasmahyla Cruz, 1990 (Anura: Hylidae) from the Atlantic Rain Forest of the States of Minas Gerais and Bahia, Brazil. Amphib-Reptilia 29:311-318.

DOORNIK, J.A. \& HANSEN, H. 2008. An omnibus test for univariate and multivariate normality. Oxford Bulletin of Economics and Statistics 70:927-939.

DREWRY, G.E. \& RAND, A.S. 1983. Characteristics of an acoustic community: Puerto Rican frogs of the genus Eleutherodactylus. Copeia 1983:941-953

DUELLMAN, W.E. \& TRUEB, L. 1986. Biology of amphibians. McGrawHill Book Company, New York, 670p.

FAIVOVICH, J., HADDAD, C.F.B., GARCIA, P.C.A., FROST, D.R., CAMPBELL, J.A. \& WHEELER, W.C. 2005. Systematic review of the frog family Hylidae, with special reference to the Hylinae: phylogenetic analysis and taxonomic revision. Bull. Am. Mus. Nat. Hist. 294:1-240.

FEIO, R.N. \& FERREIRA, P.L. 2005. Anfíbios de dois fragmentos de Mata Atlântica na Zona da Mata de Minas Gerais. Rev. Bras. Zoociências 7(1):121-128.

FEIO, R.N., BRAGA U.M.L, WIEDERHECKER, H. \& SANTOS, P.S. 1998. Anfíbios do Parque Estadual do Rio Doce (Minas Gerais). Universidade Federal de Viçosa, Instituto Estadual de Florestas, Viçosa.

FONSECA, C.R., BECKER, C.G., HADDAD, C.F.B. \& PRADO, P.I. 2008. Metamorfose. Scientific American Brasil 72:88-93.

FROST, D.R. 2009. Amphibian Species of the World: an Online Reference. Version 5.3. American Museum of Natural History, New York, USA http://research.amnh.org/herpetology/amphibia/ (ultimo acesso em 20/09/2009).

GARCIA, P.C.A. \& VINCIPROVA, G. 1998. Range extensions of some anuran species for Santa Catarina and Rio Grande do Sul States. Brazil. Herpetol. Rev. 29(2):117-118.

GARCIA, P.C.A. \& VINCIPROVA, G. 2003. Anfíbios. In Livro Vermelho da Fauna Ameaçada de Extinção no Rio Grande do Sul (C.S. Fontana, G.A. Bencke \& R.E. Reis, orgs.). EDIPUCRS, Porto Alegre, p.147-164.

GARCiA, P.C.A., LAVILlA, E., LANGONE, J.A. \& SEGALLA, M.V. 2007. Anfíbios da Região Subtropical da América do Sul: padrões de distribuição. Ciência \& Ambiente 35:65-100.

GARCIA, P.C.A., PEIXOTO, O.L. \& HADDAD, C.F.B. 2008. A new species of Hypsiboas (Anura: Hylidae) from the Atlantic Forest of Santa Catarina, Southern Brazil, with comments on its conservation status. South Am. J. of Herpetol. 3(1):27-35.

GAYER, S.M.P., KRAUSE, L. \& GOMES, N. 1988. Lista preliminar dos anfíbios da Estação Ecológica do Taim, Rio Grande do Sul, Brasil. Rev. Bras. Zool. 5(3):419-425.

GHIZONI-Jr., I.R., AZEVEDO, M.A.G. \& PORT-CARVALHO, M. 2000. Predação de Hyla nahdereri (Anura: Hylidae) por Cyclarhis gujanensis (Aves: Vireonidae) em Santa Catarina. Melopsittacus 3(3):137-139.

GIASSON, L.O.M., HARTMANN, P.A. \& GARCIA, P.C.A. 2001. Geographic distribution. Proceratophrys avelinoi. Herpetol. Rev. 32(4):272.

GISP - Programa Global de Espécies Invasoras. América do Sul invadida:a crescente ameaça das espécies exóticas invasoras. 2005. Secretaria do Gisp.

GOMES, F.B.R. \& MARTINS, I.A. 2006. Anura, Hylidae, Dendropsophus anceps: Filling gap, geographic distribution map and vocalization. Check List 2(3):22-25.

HADDAD, C.F.B. \& POMBAL Jr., J.P. 1998. Redescription of Physalaemus spiniger (Anura: Leptodactylidae) and description of two new reproductive modes. J. Herpetol. 32:557-565.

HADDAD, C.F.B. \& SAZIMA, I. 1992. Anfíbios Anuros da Serra do Japi. In História natural da Serra do Japi: ecologia e preservação de uma área florestal no sudeste do Brasil (L.P.C. Morellato, ed.). Unicamp, FAPESP, Campinas, p.188-211.

HADDAD, C.F.B. 1998. Biodiversidade dos anfíbios no Estado de São Paulo. In Biodiversidade do Estado de São Paulo, Brasil: síntese do conhecimento ao final do século XX. 6: Vertebrados (C.A. Joly \& C.E.M. Bicudo, org.). Editora FAPESP, São Paulo, p.15-26.

HADDAD, C.F.B. 2008. Anfíbios: uma análise da Lista Brasileira de Anfíbios Ameaçados de Extinção. In Livro vermelho da fauna brasileira ameaçada de extinção (A.B.M. Machado, G.M. Drummond, \& A.P. Paglia, eds.) Ministério do Meio Ambiente, Brasília, DF.

HADDAD, C.F.B., GASPARINI, J.L. \& POMBAL Jr., J.P. 1995. Geographic distribution: Hyla anceps. Herpetol. Rev. 26(4):207.

HADDAD, C.F.B., TOLEDO, L.F. \& PRADO, C.P.A. 2008. Anfíbios da Mata Atlântica/Atlantic Forest Amphibians. Neotrópica, São Paulo.

HAND, D.J. \& TAYLOR, C.C. 1987. Multivariate analysis of variance and repeated measures. London, Chapman and Hall.

HEBETS, E.A. \& PAPAJ, D.R. 2005. Complex signal function: developing a framework of testable hypotheses. Behav. Ecol. Sociobiol. 57:197-214.

HEINICKE, M.P., DUELLMAN, W.E. \& HEDGES, S.B. 2007. Major Caribbean and Central American frog faunas originated by ancient oceanic dispersal. Proc. Natl. Acad. Sci. 104:10092-10097.

HEYER, W.R. \& REID, Y.R. 2003. Does advertisement call variation coincide with genetic variation in the genetically diverse frog taxon currently known as Leptodactylus fuscus (Amphibia: Leptodactylidae)? An. Acad. Bras. Cienc. 75:39-54.

HEYER, W.R. 1973. Systematics of the marmoratus group of the frog genus Leptodactylus (Amphibia, Leptodactylidae). Nat. Hist. Mus. Los Angel. Cty Sci. Ser. 251:1-50.

HEYER, W.R. 1984. Variation, systematics, and zoogeography of Eleutherodactylus guentheri and closely related species (Amphibia: Anura: Leptodactylidae). Smithsonian Contr. Zool. 402:1-42. 
HEYER, W.R., RAND, A.S., CRUZ, C.A.G., PEIXOTO, O.L. \& NELSON, C.E. 1990. Frogs of Boracéia. Arq. Zool. 31(4):231-410.

IZECKSOHN, E. \& CARVALHO-E-SILVA, S.P. 2008. As espécies de Gastrotheca Fitzinger na Serra dos Órgãos, Estado do Rio de Janeiro, Brasil (Amphibia: Anura: Amphignathodontidae). Rev. Bras. Zool. 25(1): 110.

KRUSKAL, J.B. 1964. Nonmetric multidimensional scaling: a numerical method. Pscychometrica 2:115-121.

KWET, A. \& ANGULO, A. 2002. A new species of Adenomera (Anura, Leptodactylidae) from the Araucaria forest of Rio Grande do Sul (Brazil), with comments on the systematic status of southern populations of the genus. Alytes 20(1-2):28-43.

KWET, A. \& DI-BERNARDO, M. 1999. Pró-Mata - Anfíbios-AmphibienAmphibians. EDIPUCRS, Porto Alegre.

KWET, A. \& SOLÉ, M. 2005. Validation of Hylodes henselii Peters, 1870, from Southern Brazil and Description of Acoustic Variation in Eleutherodactylus guentheri (Anura: Leptodactylidae). J. Herpetol. 39(4):521-532.

KWET, A. \& SOLÉ, M. 2008. A new species of Trachycephalus (Anura: Hylidae) from the Atlantic Rain Forest in southern Brazil. Zootaxa 1947:53-67.

KWET, A. 2000. The genus Pseudis (Anura: Pseudidae) in Rio Grande do Sul, southern Brazil, with description of a new species. Amphib-Reptilia 21(1):39-55.

KWET, A. 2001a. Frösche im Brasilianischen Araukarienwald. Anurengemeinschaft des Araukarienwaldes von Rio Grande do Sul: Diversität, Reproduktion und Ressourcenaufteilung. Münster. Natur und Tier Verlag. 192p.

KWET, A. 2001b. Südbrasilianische Laubfrösche der Gattung Scinax mit Bemerkungen zum Geschlecht des Gattungsnamens und zum taxonomischen Status von Hyla granulata Peters, 1871. Salamandra 37:211-238.

KWET, A. 2004. Artenvielfalt in den Subtropen - Frösche im brasilianischen Araukarienwald. Biologie in unserer Zeit 34(6):170-178.

KWET, A. 2007. Bioacoustic variation in the genus Adenomera in southern Brazil, with revalidation of Leptodactylus nanus Müller, 1922 (Anura: Leptodactylidae). Mus. Nat. kd. Berl. Zool. 83:56-68.

KWET, A., STEINER, J. \& ZILLIKENS, A. 2009. A new species of Adenomera (Amphibia: Anura: Leptodactylidae) from the Atlantic rain forest in Santa Catarina, southern Brazil. Stud. Neotrop. Fauna Environ. 44(2):93-107.

LANGONE, J.A. 1997. Caraterización de Hyla guentheri Boulenger, 1886 (Amphibia, Anura, Hylidae). Cuadernos de Herpetologia 11:13-20.

LANGONE, J.A., SEGALLA, M.V., BORNSCHEIN, M. \& DE SÁ, R.O. 2008. A new reproductive mode in the genus Melanophryniscus Gallardo, 1961 (Anura: Bufonidae) with description of a new species from the State of Paraná, Brazil. South Am. J. Herpetol. 3(1):1-9.

LIMA, A.M.X., RODRIGUES, R.G., BITTENCOURT, S., CONDRATI, L.H. \& MACHADO, R.A. 2005. Geographic distribution: Bufo henseli. Herpetol. Rev. 36(2):198.

LINGNAU, R. \& BASTOS, R.P. 2002. Geographic distribution: Hyla elegans. Herpetol. Rev. 33:316-317.

LINGNAU, R. \& DI-BERNARDO, M. 2006. Geographic distribution: Pseudis cardosoi. Herpetol. Rev. 37(2):238-239.

LINGNAU, R. 2000. Geographic Distribution: Hylodes heyeri. Herpetol. Rev. 31(3):251.

LINGNAU, R. 2008. Distribuição temporal, atividade reprodutiva e vocalizações em uma assembleia de anfíbios anuros de uma Floresta Ombrófila Mista em Santa Catarina, sul do Brasil. Tese de doutorado, Pontifícia Universidade Católica do Rio Grande do Sul, Porto Alegre.

LINGNAU, R., CANEDO, C.C. \& POMBAL Jr., J.P. 2008. A new species of Hylodes (Anura: Hylodidae) from the Brazilian Atlantic Forest. Copeia, 2008(3):595-602.
LINGNAU, R., GUIMARÃES, L.D. \& BASTOS, R.P. 2004. Vocalizações de Hyla werneri (Anura, Hylidae) no Sul do Brasil. Phyllomedusa 3(2):115-120.

LITTLEJOHN, N.J. 2001. Patterns of differentiation in temporal properties of acoustic signals of anurans. In Anuran Communication. (M.J. Ryan, ed.). Oxford University Press, New York, p. 102-120.

LOPEZ, P.T., NARINS P.M., LEWIS, E.R. \& S.W. MOORE. 1988. Acoustically-induced call modification in the white-lipped frog, Leptodactylus albilabris. Anim. Behav. 36:1295-1308.

LUCAS, E.M. \& FORTES, V.B. 2008. Frog diversity in the Floresta Nacional de Chapecó, Atlantic Forest of southern Brazil. Biota Neotrop. 8(3): http:// www.biotaneotropica.org.br/v8n3/pt/fullpaper?bn00508032008+en. (ultimo acesso em 20/01/2010).

LUCAS, E.M. 2008. Diversidade e conservação de anfíbios anuros no Estado de Santa Catarina, sul do Brasil. Tese de doutorado, Universidade de São Paulo, São Paulo.

LUTZ, A. 1929. Une nouvelle spèce de Hyla (Hyla anceps). Comptes Rendus de la Société de Biologie de Paris 101(24):943-944.

LUTZ, B. \& BOKERMANN, W.C.A. 1963. A new tree frog from Santa Catarina, Brasil. Copeia 1:558-561.

LUTZ, B. 1954. Anfíbios do Distrito Federal. Mem. Inst. Oswaldo Cruz 52(1):155-238

LUTZ, B. 1973. Brazilian Species of Hyla. University of Texas Press, Austin.

MAACK, R. 1981. Geografia Física do Estado do Paraná. José Olympio Editora, Rio de Janeiro.

MACHADO, R.A. \& CONTE, C.E. 2001. Geograhic Distribution. Hyla nahdereri. Herpetol. Rev. 32(2):114.

MACHADO, R.A. \& HADDAD. C.F.B. 2001. Geographic distribution. Hyla anceps. Herpetol. Rev. 32(2):113.

MACHADO, R.A. 2004. Ecologia de assembléias de anfíbios anuros no município de Telêmaco Borba, Paraná, Sul do Brasil. Tese de doutorado, Universidade Federal do Paraná, Curitiba.

MARDIA, K.V. 1970. Measures of multivariate skewness and kurtosis. Biometrika 57(3):519-530.

MARTINS, I.A., ALMEIDA, S.C. \& JIM, J. 2006. Calling sites and acoustic partitioning in species of the Hyla nana and rubicundula groups (Anura, Hylidae). Herpetological Journal 16:239-247.

MEDEIROS, J.D., SAVI, M. \& BRITO, B.F.A. 2005. Seleção de áreas para criação de Unidades de Conservação na Floresta Ombrófila Mista. Biotemas 18(2):33-50

MENIN, M., WALDEZ, F. \& LIMA, A.P. 2008. Temporal variation in the abundance and number of species of frogs in 10.000 ha of a forest in central amazonia, Brazil. South Am. J. Herpetol. 3(1):68-81.

MIKICH, S.B. \& BÉRNILS, R.S. 2004. Livro Vermelho da Fauna Ameaçada no Estado do Paraná. http://www.pr.gov.br/iap (último acesso em 29/08/2009).

MINTER, L.R. 1997. Advertisement call structure and morphology of Breviceps mossambicus Peters and B. poweri Parker (Anura: Microhylidae) from northern Mozambique. Ann. Natal Mus. 38:5-19.

MORESCO, R.M., MARGARIDO, V.P., NAZARIO, P.D., SCHMIT, R.A. \& TRECO, F.R. 2009. Amphibia, Anura, Hylidae, Scinax granulatus: Distribution extension. Check List 5(1):86-88.

MÜLLER, L. 1922. Über eine Sammlung Froschlurche von Sta. Catharina nebst Beschreibung zweier neuer Arten. Bl. Aquar. Terrarkde. 33:167-171.

NASCIMENTO, L.B. \& FEIO, R.N. 1999. Hyla anceps. Geographic distribution. Herpetol. Rev. 30(1):49-50.

NOMURA, F. Análise em multi-escala espacial da biodiversidade: padrões de diversidade e estrutura de taxocenoses de anfíbios anuros. Tese de doutorado, Universidade Estadual Paulista, Rio Claro.

ORRICO, V.G.D., LINGNAU, R. \& GIASSON, L.O.M. 2009. The advertisement call of Dendropsophus nahdereri (Anura, Hylidae, Dendropsophini). South Am. J. Herpetol. 4(3):295-299. 
OVERBECK, G.E., MÜLLER, S.C., FIDELIS, A. PFADENHAUER, J., PILLAR, V.D., BLANCO, C.C., BOLDRINI, I., BOTH, R. \& FORNECK, E.D. 2007. Brazil's negleted biome: the South Brazilian Campos. Perspect. Plant Ecol. Evol. Syst. (9):101-116.

PARTAN, S. \& MARLER, P. 1999. Communication goes multimodal. Science 283:1272-1273

PARTAN, S. \& MARLER, P. 2005. Issues in the classification of multimodal communication signals. Am. Nat. 166:231-245.

PEIXOTO, O.L. \& GOMES, M.R. 1999. The tadpole of Hyla nahdereri Lutz and Bokermann, 1973. J. Herpetol. 33(3):447-479.

PETERS, W. 1870. Über neue Amphibien des Königlich zoologischen Museums. Monatsberichte der Berliner Akademie der Wissenschaften 1870:641-652.

PETERS, W. 1871. Über einige Arten der herpetologischen Sammlung des Berliner zoologischen Museums. Monatsberichte der königlich Akademie der Wissenschaften zu Berlin 1871: 644-652.

PIMENTA, B.V.S, CRUZ, C.A.G. \& SILVANO, D.L. 2005. A new species of the genus Physalaemus Fitzinger, 1826 (Anura, Leptodactylidae) from the Atlantic Rain Forest of southern Bahia, Brazil. Amphib-Reptilia 26(2005):201-210.

POMBAL Jr. \& GORDO, M. 2004. Anfíbios anuros da Juréia. In Estação Ecológica Juréia-Itatins. Ambiente Físico, Flora e Fauna. (O.A.V. Marques \& W. Duleba, eds.). Ribeirão Preto, Holos, p.243-256.

POMBAL Jr., J.P. \& GORDO, M. 1991. Duas novas espécies de Hyla da Floresta Atlântica do estado de São Paulo (Amphibia, Anura). Mem. Inst. Butantan 53(11):135-144.

RIBEIRO, L.F., ALVES, A.C.R, HADDAD, C.F.B. \& DOS REIS, S.F. 2005 Two new species of Brachycephalus Günther, 1858 from the state of Paraná, Southern Brazil (Amphibia, Anura, Brachycephalidae). Bol. Mus. Nac. Rio J. Zool. 519:1-18.

ROCHA, V. J., MACHADO, R.A., FILIPAKI, S.A., FIER, I.S.N. \& PUCCI, J.A.L. 2003. A biodiversidade da Fazenda Monte Alegre da Klabin S.A. no Estado do Paraná. In VIII Congresso Florestal Brasileiro, São Paulo. $1 \mathrm{CD}$ room.

RODERJAN, C.V., GALVÃO, F., KUNIYOSHI, Y.S., \& HATSCHBACK, G. 2002. As unidades fitogeográficas do Estado do Paraná. Ciência \& Ambiente 24:75-92.

ROLIM, D.C., MAFFEI, F., SENE, R.K., MEDOLAGO, C.A.B., VERNINI, T.H., UBAID, F.K. \& JIM, J. 2008. Amphibia, Anura, Hylidae, Dendropsophus anceps: Distribution extension in state of São Paulo, Brazil. Check List 4(3):358-361.

ROSSA-FERES, D.C. \& JIM, J. 2001. Similaridade do sítio de vocalização em uma comunidade de anfíbios anuros na região noroeste do Estado de São Paulo, Brasil. Rev. Bras. Zool. 18(2):439-454.

SANTOS, T.G., VASCONCELOS, T.S., ROSSA-FERES, D.C. \& HADDAD, C.F.B. 2009. Anurans of a seasonally dry tropical forest: Morro do Diabo State Park, São Paulo State, Brazil. J. Nat. Hist. 43:973-993.

SEGALLA, M.V. \& LANGONE, J.A. 2004. Anfibios. In Livro vermelho da fauna ameaçada no estado do Paraná (S.B. Mikich \& R.S. Bérnils, eds.). Instituto Ambiental do Paraná - IAP, Curitiba, p.539-577.

SILVA, H.R. \& ALVES-SILVA, R. 2008. New coastal and insular species of the bromeligenous Scinax perpusillus group, from the State of Rio de Janeiro, Brazil (Anura, Hylidae). Zootaxa 1914:34-44.
SILVANO, D.L. \& PIMENTA, B.V.S. 2003. Diversidade de anfíbios na Mata Atlântica do Sul da Bahia. In Corredor de Biodiversidade na Mata Atlântica do Sul da Bahia (P. I. Prado, E. C. Landau, R. T. Moura, L. P. S. Pinto, G. A. B. Fonseca \& K. Alger, orgs.). IESB,CI,CABS,UFMG,UNICAMP, Ilhéus, CD-ROM.

SILVANO, D.L. \& SEGALLA, M.V. 2005. Conservação de Anfíbios no Brasil. Megadiversidade 1(1):79-86.

SOCIEDADE BRASILEIRA DE HERPETOLOGIA - SBH 2010. Lista de espécies de anfíbios do Brasil. Sociedade Brasileira de Herpetologia (SBH) http://www.sbherpetologia.org.br/checklist/anfibios.htm (último acesso em 30/06/2010).

STEINBACH-PADILHA, G.C. 2008. A new species of Melanophryniscus (Anura, Bufonidae) from the Campos Gerais region of southern Brazil. Phyllomedusa 7(2):99-108.

TER BRAAK, C.J.F. 1994. Canonical community ordination. Part 1: basic theory and linear methods. Ecoscience (1):127-140.

THOMAS, R. 1966. New species of Antillean Eleutherodactylus. Q. J. Florida Acad. Sci. 28:375-391.

THE INTERNATIONAL UNION FOR CONSERVATION OF NATURE - IUCN 2009. IUCN Red List of Threatened Species. Version 2009.1. IUCN, Gland, Switzerland. www.iucnredlist.org (último acesso em 29/08/2009).

VAZ-SILVA, W., DI-BERNARDO, M., GUIMARÃES, L.D. \& BASTOS, R.P. 2007. Territoriality, agonistic behaviour, and vocalization in Pseudis bolbodactylus A. Lutz, 1925 (Anura: Hylidae) from Central Brazil. Salamandra 43(1):35-42.

WEBER, L.N., GONZAGA, L.P. \& CARVALHO-E-SILVA, S.P. 2005. Uma nova espécie de Physalaemus Fitzinger, 1826 da Mata Atlântica de baixada do Estado do Rio de Janeiro, Brasil (Amphibia, Anura, Leptodactylidae). Arq. Mus. Nac. Rio J. 63(4):677-684.

WEIRICH NETO, P.H. \& ROCHA, C.H. 2007. Caracterização da produção agropecuária e implicações ambientais nos Campos Gerais. In Patrimônio natural dos Campos Gerais do Paraná. Ponta Grossa (M.S. Melo, R.S. Moro \& G.C. Burigo, eds.). Editora UEPG, Ponta Preta, p.181-190.

WELLS, K.D. 1977. The social behaviour of anuran amphibians. Anim. Behav. 25:666-693.

WELLS, K.D. 2007. The ecology and behavior of amphibians. The University of Chicago Press, Chicago.

WOGEL, H., ABRUNHOSA, P.A. \& POMBAL Jr., J.P. 2000. Girinos de cinco espécies de anuros do Sudeste do Brasil (Amphibia: Hylidae, Leptodactylidae, Microhylidae). Bol. Mus. Nac. Rio J. Zool. 427:1-16.

WYNN, A. \& HEYER, W.R. 2001. Do geographically widespread species of tropical amphibians exist? An estimate of genetic relatedness within the Neotropical frog Leptodactylus fuscus (Schneider 1799) (Anura: Leptodactylidae). Trop. Zool. (Florence) 14:255-285.

ZANK, C., DI-BERNARDO, M., LINGNAU, R., COLOMBO, P., FUSINATTO, L.A. \& FONTE, L.F.M. 2008. Calling activity and agonistic behavior of Pseudis minuta Günther, 1858 (Anura, Hylidae, Hylinae) in the Reserva Biológica do Lami, Porto Alegre, Brazil. South American Journal of Herpetology 3(1):51-57.

ZAR, J.H. 1999. Biostatistical analysis. 4 ed. Prentice-Hall, New Jersey, $663 \mathrm{p}$. 


\section{Anexo 1}

Anexo 1. Lista dos exemplares examinados, com indicação do sexo e CRC (comprimento-rostro cloacal em mm) dos exemplares, e detalhes do número de tombamento na coleção (sigla da coleção e número de tombo do exemplar).

Annex 1. List of specimens examined. SVL = snout-vent length, $\widehat{\partial}=$ male, $\phi=$ female.

\begin{tabular}{|c|c|c|c|c|}
\hline Espécie & CRC & Localidade & Data de coleta & Coleção/Número \\
\hline I. henselii ${ }^{\wedge}$ & 22,49 & Fazenda Rio Grande, PR & $10 / 05 / 2002$ & DZSJRP 8860 \\
\hline I. henselii $\widehat{\jmath}$ & 10,58 & Fazenda Rio Grande, PR & $01 / 10 / 2002$ & DZSJRP 8885 \\
\hline I. henselii ${ }_{0}$ & 24,40 & Fazenda Rio Grande, PR & $22 / 01 / 2002$ & DZSJRP 8889 \\
\hline I. henselii $\widehat{\jmath}$ & 23,79 & São José dos Pinhais, PR & $26 / 10 / 2001$ & DZSJRP 6199 \\
\hline I. henselii $\widehat{\supset}$ & 14,20 & São José dos Pinhais, PR & $31 / 10 / 1999$ & DZSJRP 6198 \\
\hline I. henselii §̊ & 23,70 & São José dos Pinhais, PR & $01 / 02 / 2003$ & DZSJRP 6183 \\
\hline I. henselii ${ }^{\Uparrow}$ & 36,31 & São José dos Pinhais, PR & $01 / 11 / 2004$ & DZSJRP 6184 \\
\hline I. henselii $\widehat{\jmath}$ & 33,21 & São José dos Pinhais, PR & $01 / 11 / 2004$ & DZSJRP 6185 \\
\hline I. henselii $\overbrace{}^{\Uparrow}$ & 32,30 & São José dos Pinhais, PR & 04/07/2003 & DZSJRP 6188 \\
\hline I. henselii $\widehat{\partial}$ & 34,32 & São José dos Pinhais, PR & $21 / 09 / 2003$ & DZSJRP 6224 \\
\hline I. henselii $\widehat{\jmath}$ & 21,61 & São José dos Pinhais, PR & $24 / 08 / 2002$ & DZSJRP 6225 \\
\hline I. henselii $\widehat{O}$ & 19,01 & São José dos Pinhais, PR & $13 / 05 / 2003$ & DZSJRP 6304 \\
\hline I. henselii $\widehat{\partial}$ & 22,10 & Vargem Bonita, SC & $30 / 11 / 2008$ & DZSJRP 13506 \\
\hline I. henselii $\widehat{\partial}$ & 22,30 & São José dos Pinhais, PR & 09/01/2008 & DZSJRP 13507 \\
\hline I. henselii ${ }_{+}$ & 36,40 & FLONA de Irati, PR & $02 / 12 / 2008$ & DZSJRP 13513 \\
\hline I. henselii $\widehat{\partial}$ & 22,90 & Vargem Bonita, SC & $30 / 11 / 2008$ & DZSJRP 13351 \\
\hline I. henselii $\widehat{O}$ & 26,40 & PARNA das Araucárias, SC & $22 / 09 / 2007$ & DZSJRP 13191 \\
\hline 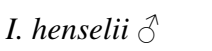 & 25,10 & PARNA das Araucárias, SC & $22 / 09 / 2007$ & DZSJRP 13192 \\
\hline 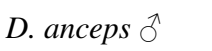 & 40,43 & Ribeirão Claro, PR & $18 / 02 / 2006$ & DZSJRP 10804 \\
\hline 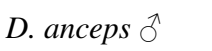 & 39,09 & Ribeirão Claro, PR & $18 / 02 / 2006$ & DZSJRP 10805 \\
\hline D. anceps ठิ & 42,70 & Ribeirão Claro, PR & $11 / 02 / 2007$ & DZSJRP 11610 \\
\hline 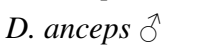 & 40,57 & Ribeirão Claro, PR & $11 / 02 / 2007$ & DZSJRP 11616 \\
\hline D. anceps $\widehat{\widehat{\sigma}}$ & 41,25 & Ibaiti, PR & $13 / 02 / 2009$ & DZSJRP 13543 \\
\hline D. anceps ㅇ & 44,40 & Ibaiti, PR & $14 / 02 / 2009$ & DZSJRP 13556 \\
\hline D. anceps $q$ & 39,20 & Ibaiti, PR & $13 / 11 / 2009$ & DZSJRP 13904 \\
\hline D. anceps 우 & 36,80 & Ibaiti, PR & $13 / 11 / 2009$ & DZSJRP 13905 \\
\hline D. anceps $q$ & 37,20 & Figueira, PR & $13 / 11 / 2009$ & DZSJRP 13906 \\
\hline 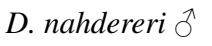 & 43,47 & São José dos Pinhais, PR & $02 / 03 / 2003$ & DZSJRP 6164 \\
\hline 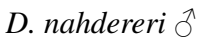 & 44,63 & São José dos Pinhais, PR & $31 / 09 / 2001$ & DZSJRP 6165 \\
\hline 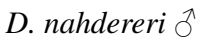 & 44,37 & São José dos Pinhais, PR & $19 / 09 / 2003$ & DZSJRP 6166 \\
\hline D. nahdereri ${ }^{\Uparrow}$ & 40,23 & São José dos Pinhais, PR & $19 / 01 / 2004$ & DZSJRP 6289 \\
\hline D. nahdereri $\widehat{\jmath}$ & 42,30 & Vargem Bonita, SC & $02 / 09 / 2007$ & DZSJRP 13136 \\
\hline D. nahdereri $\widehat{\jmath}$ & 44,00 & Vargem Bonita, SC & $02 / 09 / 2007$ & DZSJRP 13137 \\
\hline D. nahdereri ${ }^{\top}$ & 39,30 & Vargem Bonita, SC & $02 / 09 / 2007$ & DZSJRP 13138 \\
\hline D. nahdereri ${ }^{\top}$ & 43,30 & Vargem Bonita, SC & $02 / 09 / 2007$ & DZSJRP 13139 \\
\hline D. nahdereri $\widehat{\sigma}^{\top}$ & 45,10 & Vargem Bonita, SC & $02 / 09 / 2007$ & DZSJRP 13140 \\
\hline 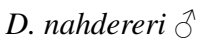 & 42,80 & Vargem Bonita, SC & $02 / 09 / 2007$ & DZSJRP 13141 \\
\hline 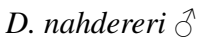 & 43,15 & General Carneiro, PR & $17 / 10 / 2007$ & DZSJRP 13235 \\
\hline 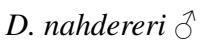 & 42,80 & General Carneiro, PR & $17 / 10 / 2007$ & DZSJRP 13236 \\
\hline D. nahdereri $\widehat{\sigma}$ & 40,50 & Vargem Bonita, SC & $23 / 10 / 2008$ & DZSJRP 13484 \\
\hline D. nahdereri ㅇ & 50,15 & Vargem Bonita, SC & $23 / 10 / 2008$ & DZSJRP 13483 \\
\hline P. cardosoi ठิ & 38,00 & REVS dos Campos de Palmas, PR & 09/09/2008 & DZSJRP 13384 \\
\hline P. cardosoi $\widehat{O}$ & 42,80 & REVS dos Campos de Palmas, PR & 09/09/2008 & DZSJRP 13385 \\
\hline 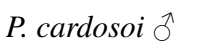 & 42,80 & REVS dos Campos de Palmas, PR & $10 / 09 / 2008$ & DZSJRP 13391 \\
\hline 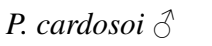 & 43,60 & REVS dos Campos de Palmas, PR & $10 / 09 / 2008$ & DZSJRP 13393 \\
\hline P. cardosoi $q$ & 53,90 & REVS dos Campos de Palmas, PR & $10 / 09 / 2008$ & DZSJRP 13392 \\
\hline S. granulatus §̄ & 35,65 & Vergem Bonita, SC & $28 / 11 / 2006$ & DZSJRP 13009 \\
\hline S. granulatus $\widehat{0}$ & 31,35 & General Carneiro, PR & $03 / 12 / 2006$ & DZSJRP 13028 \\
\hline S. granulatus ठิ & 32,25 & Vergem Bonita, SC & $28 / 01 / 2008$ & DZSJRP 13187 \\
\hline
\end{tabular}


Anexo 1. Continuação...

\begin{tabular}{|c|c|c|c|c|}
\hline Espécie & CRC & Localidade & Data de coleta & Coleção/Número \\
\hline S. granulatus $\widehat{0}$ & 29,45 & General Carneiro, PR & $22 / 02 / 2008$ & DZSJRP 13091 \\
\hline S. granulatus $\hat{0}$ & 33,40 & Vergem Bonita, SC & $02 / 11 / 2007$ & DZSJRP 13152 \\
\hline S. granulatus $\hat{0}$ & 34,60 & General Carneiro, PR & $20 / 09 / 2007$ & DZSJRP 13184 \\
\hline S. granulatus $\hat{O}^{-}$ & 33,00 & General Carneiro, PR & $20 / 09 / 2007$ & DZSJRP 13185 \\
\hline S. granulatus $\widehat{0}$ & 31,55 & General Carneiro, PR & $20 / 09 / 2007$ & DZSJRP 13186 \\
\hline S. granulatus $\hat{\sigma}$ & 33,85 & PARNA das Araucárias, SC & $22 / 09 / 2007$ & DZSJRP 13219 \\
\hline S. granulatus $\hat{\sigma}$ & 35,65 & PARNA das Araucárias, SC & $22 / 09 / 2007$ & DZSJRP 13220 \\
\hline S. granulatus $\hat{\sigma}$ & 32,50 & Vargem Bonita, SC & $03 / 12 / 2007$ & DZSJRP 13386 \\
\hline S. granulatus $\hat{O}$ & 32,90 & PARNA das Araucárias, SC & $20 / 10 / 2007$ & DZSJRP 13256 \\
\hline S. granulatus $\hat{0}$ & $32,0032,50$ & REVS dos Campos de Palmas, PR & $09 / 09 / 2008$ & DZSJRP 13306 \\
\hline S. granulatus $\hat{O}$ & 33,45 & REVS dos Campos de Palmas, PR & $10 / 09 / 2008$ & DZSJRP 13389 \\
\hline S. granulatus $\widehat{0}$ & 36,40 & General Carneiro, PR & $26 / 09 / 2008$ & DZSJRP 13407 \\
\hline S. granulatus $\widehat{0}$ & 34,80 & General Carneiro, PR & $26 / 09 / 2008$ & DZSJRP 13408 \\
\hline S. granulatus $\hat{0}$ & 34,40 & Vargem Bonita, SC & $28 / 09 / 2008$ & DZSJRP 13413 \\
\hline S. granulatus $\hat{0}$ & 34,00 & REVS dos Campos de Palmas, PR & $30 / 09 / 2008$ & DZSJRP 13419 \\
\hline S. granulatus $\widehat{\partial}$ & 33,10 & REVS dos Campos de Palmas, PR & $30 / 09 / 2008$ & DZSJRP 13422 \\
\hline S. granulatus $\widehat{\partial}$ & 31,95 & REVS dos Campos de Palmas, PR & $30 / 09 / 2008$ & DZSJRP 13423 \\
\hline S. granulatus $\widehat{\partial}$ & 33,50 & REVS dos Campos de Palmas, PR & $30 / 09 / 2008$ & DZSJRP 13426 \\
\hline S. granulatus $\widehat{\partial}$ & 32,70 & REVS dos Campos de Palmas, PR & $30 / 09 / 2008$ & DZSJRP 13428 \\
\hline S. granulatus $\hat{\sigma}$ & 33,45 & REVS dos Campos de Palmas, PR & $21 / 10 / 2008$ & DZSJRP 13474 \\
\hline S. granulatus $\hat{\sigma}$ & 34,45 & REVS dos Campos de Palmas, PR & $21 / 10 / 2008$ & DZSJRP 13477 \\
\hline S. granulatus $\widehat{0}$ & 36,80 & Vargem Bonita, SC & $23 / 10 / 2008$ & DZSJRP 13485 \\
\hline S. granulatus $\hat{0}$ & 33,80 & Vargem Bonita, SC & $30 / 11 / 2008$ & DZSJRP 13503 \\
\hline T. dibernardoi $\hat{\sigma}$ & 62,94 & Fazenda Rio Grande, PR & $24 / 09 / 2002$ & DZSJRP 8810 \\
\hline T. dibernardoi $\hat{\sigma}$ & 66,46 & Fazenda Rio Grande, PR & $24 / 09 / 2002$ & DZSJRP 8811 \\
\hline T. dibernardoi $\hat{\sigma}$ & 62,83 & Fazenda Rio Grande, PR & $27 / 09 / 2002$ & DZSJRP 8812 \\
\hline T. dibernardoi $\widehat{\partial}$ & 64,34 & Fazenda Rio Grande, PR & $27 / 09 / 2002$ & DZSJRP 8813 \\
\hline T. dibernardoi $\hat{\jmath}$ & 60,85 & Fazenda Rio Grande, PR & $24 / 09 / 2002$ & DZSJRP 8821 \\
\hline T. dibernardoi $\widehat{\partial}$ & 62,40 & PARNA das Araucárias, SC & $02 / 11 / 2007$ & DZSJRP 13162 \\
\hline 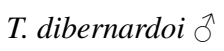 & 63,10 & PARNA das Araucárias, SC & $02 / 11 / 2007$ & DZSJRP 13163 \\
\hline 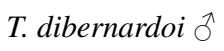 & 61,30 & PARNA das Araucárias, SC & $02 / 11 / 2007$ & DZSJRP 13164 \\
\hline 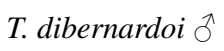 & 64,40 & PARNA das Araucárias, SC & $02 / 11 / 2007$ & DZSJRP 13165 \\
\hline T. dibernardoi $\widehat{\widehat{O}}$ & 66,55 & PARNA das Araucárias, SC & $02 / 11 / 2007$ & DZSJRP 13166 \\
\hline T. dibernardoi $\widehat{\widehat{O}}$ & 66,20 & PARNA das Araucárias, SC & $02 / 11 / 2007$ & DZSJRP 13167 \\
\hline T. dibernardoi $\widehat{\widehat{O}}$ & 62,50 & PARNA das Araucárias, SC & $02 / 11 / 2007$ & DZSJRP 13168 \\
\hline 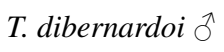 & 70,60 & PARNA das Araucárias, SC & $02 / 11 / 2007$ & DZSJRP 13169 \\
\hline T. dibernardoi $\widehat{\jmath}$ & 63,80 & PARNA das Araucárias, SC & $02 / 11 / 2007$ & DZSJRP 13170 \\
\hline T. dibernardoi $\widehat{\jmath}$ & 67,05 & PARNA das Araucárias, SC & $02 / 11 / 2007$ & DZSJRP 13171 \\
\hline 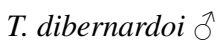 & 59,70 & PARNA das Araucárias, SC & $02 / 11 / 2007$ & DZSJRP 13172 \\
\hline T. dibernardoi $\widehat{\jmath}$ & 66,25 & PARNA das Araucárias, SC & $02 / 11 / 2007$ & DZSJRP 13173 \\
\hline T. dibernardoi $\hat{\jmath}$ & 62,45 & PARNA das Araucárias, SC & $02 / 11 / 2007$ & DZSJRP 13174 \\
\hline T. dibernardoi 우 & 77,50 & PARNA das Araucárias, SC & $02 / 11 / 2007$ & DZSJRP 13175 \\
\hline 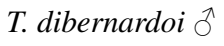 & 62,15 & PARNA das Araucárias, SC & $02 / 11 / 2007$ & DZSJRP 13259 \\
\hline 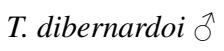 & 64,40 & PARNA das Araucárias, SC & $02 / 11 / 2007$ & DZSJRP 13161 \\
\hline T. dibernardoi $\widehat{\widehat{\sigma}}$ & 60,80 & Fazenda Rio Grande & $16 / 12 / 2007$ & DZSJRP 13320 \\
\hline L. nanus $\widehat{\partial}$ & 18,60 & PARMU São Luis de Tolosa, PR & $11 / 10 / 2008$ & DZSJRP 13446 \\
\hline L. nanus ${ }^{\pi}$ & 18,90 & PARMU São Luis de Tolosa, PR & $11 / 10 / 2008$ & DZSJRP 13447 \\
\hline L. nanus $\widehat{\partial}$ & 17,40 & PARMU São Luis de Tolosa, PR & $14 / 11 / 2008$ & DZSJRP 13495 \\
\hline
\end{tabular}

